\title{
Simulation of More Realistic Upper-Ocean Processes from an OGCM with a New Ocean Mixed Layer Model
}

\author{
Yign NoH AND Chan Joo JANG* \\ Department of Atmospheric Sciences, Yonsei University, Seoul, Korea \\ Toshio Yamagata \\ Department of Earth and Planetary Physics, University of Tokyo, Tokyo, Japan \\ Peter C. Chu \\ Department of Oceanography, Naval Postgraduate School, Monterey, California \\ CHEOL-Ho KIM \\ Korean Oceanographic Research and Development Institute, Ansan, Korea
}

(Manuscript received 10 July 2000, in final form 25 July 2001)

\begin{abstract}
A new ocean mixed layer model (OMLM) was embedded into an ocean general circulation model (OGCM) with the aim of providing an OGCM that is ideal for application to a climate model by predicting the sea surface temperature (SST) more accurately. The results from the new OMLM showed a significant improvement in the prediction of SST compared to the cases of constant vertical mixing and the vertical mixing scheme by Pacanowski and Philander. More accurate prediction of the SST from the new OMLM reduces the magnitude of the restoring term in the surface heat flux and thus provides a simulated ocean that can be coupled to the atmospheric general circulation model more naturally. The new OMLM was also shown to improve various other features of the OGCM such as the mixed layer depth and the equatorial circulation.
\end{abstract}

\section{Introduction}

Extensive efforts have been devoted to the advance of the ocean general circulation model (OGCM) during last few decades, with the intention of simulating the present climate and predicting the future climate. For the purpose of climate prediction, the OGCM must be coupled to an atmospheric general circulation model (AGCM), along with the properly represented air-sea interaction. This particularly requires accurate prediction of the sea surface temperature (SST) from the OGCM. Hence, we should regard the accurate prediction of SST as the most important prerequisite of the OGCM for its application to climate prediction.

From the early stage of OGCMs the surface boundary condition of temperature in OGCMs has been given

\footnotetext{
*Current affiliation: Korean Oceanographic Research and Development Institute, Ansan, Korea.
}

Corresponding author address: Prof. Yign Noh, Department of Atmospheric Sciences, Yonsei University, Seoul 120-749, Korea. E-mail: noh@atmos.yonsei.ac.kr predominantly by the restoring boundary condition in which the simulated SST is restored toward the climatological SST. That is, the surface heat flux $Q$ is given by

$$
Q=\rho C_{p} \Delta z_{1}\left(T_{S}^{*}-T_{S}\right) / \tau,
$$

or it is incorporated into the equation of temperature in the first layer as

$$
\frac{\partial T}{\partial t}+\cdots=\frac{\left(T_{S}^{*}-T_{S}\right)}{\tau} .
$$

Here $\tau$ is the restoring timescale, $T_{S}$ is the temperature of the first model layer, $T_{S}^{*}$ is the observed SST, $\rho$ is the density, $C_{p}$ is the specific heat of seawater, and $\Delta z_{1}$ is the thickness of the first layer of the model.

The restoring boundary condition has been favored in particular since it insures that the simulated SST will not drift far from the climatological SST and, thus, helps to reproduce an ocean that is close to the climatological ocean, even in the presence of considerable defectiveness of the model. Its widespread use is also attributed to the fact that there were no available reliable clima- 
tological heat flux data and that the simulation solely based on the prescribed heat flux suffers from drift from the climatological values with time because of the absence of feedback (Cane 1994; Seager et al. 1995; McWilliams 1996).

Nonetheless, the restoring boundary condition imposes various serious problems for realistic simulation of the ocean using an OGCM. The most conspicuous defect is that the accurate prediction of SST leads to the unrealistic situation of no heat flux at the sea surface. It also diminishes the amplitude of the annual cycle and causes a phase lag compared to the climatological SST (Haidvogel and Bryan 1992). Meanwhile, it leads to weakened convective overturning and thus reduced thermohaline circulation since it tries to maintain the climatological SST (Mikolajewicz and Maier-Reimer 1994; Cai and Chu 1996; Toggweiler et al. 1989). Accordingly, it was pointed out that the so-called thermohaline catastrophe may be related to inadequacy of the restoring boundary condition (Cai and Godfrey 1995; Rahmstorf and Willebrand 1995). Moreover, strong artificial damping to the climatological SST suppresses the variability at the sea surface, which must originate naturally from the internal ocean dynamics, and thus leads to the serious underestimation of sea surface height variability and eddy kinetic energy in the high-resolution OGCM compared to the satellite data (Stammer et al. 1996; Ishikawa et al. 1997).

The restoring boundary condition of the OGCM is particularly inappropriate in a climate model in which heat flux is calculated directly from the AGCM instead of by the restoring term. Relaxation of the restoring term for the coupling to the AGCM leads to the generation of spurious oscillatory behavior in the OGCM (Cai and Chu 1996). It may be caused by the fact that the restoring boundary condition forces the simulated result toward an unnatural condition dictated by the climatological SST, thus making it inconsistent with the internal ocean dynamics controlled by the model.

Another problem regarding the restoring boundary condition employed in OGCMs involves the magnitude of the restoring timescale $\tau$. The restoring timescale used in present OGCMs is typically about 30 days (Semtner and Chervin 1992; Stammer et al. 1996; Marotzke and Willebrand 1991). However, analyses of the observed data revealed that sensitivity of the surface heat flux to variations of SST must be much weaker than presumed in the above values, which implies that $\tau$ must be much longer (Seager et al. 1995; Barnier 1998; Chu et al. 1998). For example, Barnier (1998) and Frankigonoul et al. (1998) suggested that the restoring timescale must be at least twice as long.

Recently, improvement of the restoring boundary condition has been attempted by combining the restoring term with the climatological heat flux $Q^{*}$. That is,

$$
Q=Q^{*}+\rho C_{p} \Delta z_{1}\left(T_{S}^{*}-T_{S}\right) / \tau \text {. }
$$

We will call the surface thermal forcing given in the form of (3) the combined boundary condition hereafter in the present paper. It has become increasingly widely used as more reliable data for $Q^{*}$ has become available (Ezer and Mellor 1992; Masumoto and Yamagata 1996; Mikolajewicz and Maier-Reimer 1994; Sterl and Kattenberg 1994; Barnier et al. 1995; Stammer et al. 1996; Maltrud et al. 1998). They also suggested that the value of $\tau$ can be interpreted as

$$
\tau=-\frac{\rho C_{p} \Delta z_{1}}{\left(\partial Q / \partial T_{S}\right)_{T_{S}^{*}}}
$$

(Masumoto and Yamagata 1996; Barnier et al. 1995; Maltrud et al. 1998).

One obvious advantage of the combined boundary condition over the restoring boundary condition is that, if the model can predict SST accurately, the heat flux in the model approaches the climatological heat flux. As the restoring term becomes negligible, the model SST becomes controlled by the ocean dynamics rather than the restoring term (Barnier 1998). This will help to remove most problems associated with the restoring boundary condition mentioned above.

This implies, however, that the restoring term in (3) should be sufficiently small compared to $Q^{*}$ for the combined boundary condition to really yield improved results of the OGCM. Nonetheless, it has not been examined whether the restoring term is sufficiently smaller than $Q^{*}$ in the aforementioned applications of the combined boundary condition. Of course, this cannot be obtained simply by increasing $\tau$ because the simulated SST $T_{S}$ deviates farther from the climatological SST $T_{S}^{*}$ as the restoring becomes weaker with increasing $\tau$.

The reduction of the restoring term $\left(T_{S}^{*}-T_{S}\right) / \tau$ can be obtained only by predicting the SST accurately from the model. The most important factor in the accurate prediction of SST is the ocean mixed layer process, which controls the vertical transfer of heat below the sea surface. This suggests that the improved OGCM with realistic surface heat flux and sufficiently small restoring term cannot be obtained simply by switching from the restoring boundary condition to the combined boundary condition, but should be accompanied by the improvement of the mixed layer process in the OGCM as well.

Recently, Stammer et al. (1996), Maltrud et al. (1998), and Jiang et al. (1999) compared the results of OGCMs using the restoring and combined boundary conditions and observed some improvements such as enhancement of western boundary currents and the poleward heat transport. However, it is not yet clear whether the combined boundary condition can provide more realistic upper-ocean conditions, such as in the predictions of SST and surface heat flux, than the restoring boundary condition. Moreover, they did not account for the effects of mixed layer processes.

Various ocean mixed layer models (OMLM) have been developed to predict SST and mixed layer depth 
(MLD), usually for a horizontally homogeneous upper ocean. Since Pacanowski and Philander's (1981) simple prescription. For vertical mixing affected by stratification, several OMLMs have been embedded into the OGCM, and their effects were tested. The embedded OMLM is either the turbulence closure model (Mellor and Yamada 1982; Large et al. 1994; Gaspar et al. 1990) or the bulk model (Kraus and Turner 1967; Price et al. 1986). The former is usually applied to the $z$ - or $\sigma$ coordinate models, and the latter to the isopycnal models. For example, Rosati and Miyakoda (1988) and Ezer (2000) examined the Mellor-Yamada model in the OGCM, Large et al. (1997) and Large and Gent (1999) examined the K-profile parameterization (KPP) model by Large et al. (1994), and Blanke and Delecluse (1993) examined the model by Gaspar et al. (1990). On the other hand, Sterl and Kattenberg (1994), Oberhuber (1993), and Bleck et al. (1989) combined bulk-type models, similar to Kraus and Turner (1967), into an OGCM. Meanwhile, Chen et al. (1994) suggested another bulk model that hybridizes the Kraus-Turner model and the model by Price et al. (1986).

Nevertheless, it has not been shown clearly that the prediction of the global SST could be significantly improved by including the OMLM. For example, the Mellor-Yamada model was found to cause excessively high SST under heating, and thus it could not provide much improvement compared to the case without the OMLM under monthly mean surface forcing (Rosati and Miyakoda 1988). Large et al. (1997) reported a less than $5 \%$ decrease in the rms of the potential temperature anomaly over the upper $903 \mathrm{~m}$ when the KPP model was included, but they did not examine the effects of the OMLM on spatial and temporal variations of the SST anomaly. Meanwhile, in most other cases the application was restricted to a regional ocean (Blanke and Delecluse 1993; Sterl and Kattenberg 1994; Chen et al. 1994; Large and Gent 1999; Ezer 2000).

Therefore, in this paper we attempted to reproduce more realistic upper ocean processes such as SST and MLD over the global ocean by including a new OMLM in an OGCM and to realize more realistic surface heat flux in the OGCM. In this way we hope to provide an OGCM that can be naturally coupled to an AGCM.

Investigation was made through three stages of experiments. First, we examined an OGCM under both restoring and combined boundary conditions for temperature for the case of constant vertical mixing. Second, we investigated OGCMs under the combined boundary condition with different mixed layer processes: the constant vertical mixing, the widely used vertical mixing scheme by Pacanowski and Philander (1981), and a new OMLM. Here a new OMLM was developed for the OGCM based on the model by Noh and Kim (1999). Finally we repeated the experiments with longer restoring timescale for the case of the OGCM with the new OMLM. The results were analyzed from the perspective of the improvement of the upper-ocean process.

\section{Model and experiment}

\section{a. $O G C M$}

This study employed the Pacanowski et al. (1991) version of the Bryan-Cox-Semtner OGCM. The model domain covered the global ocean up to $80^{\circ}$ latitude in both hemispheres. The horizontal grid spacing was $1^{\circ}$ in both latitude and longitude. The vertical grids were made of 21 levels whose thickness increased with depth from $20 \mathrm{~m}$ at the surface to $1000 \mathrm{~m}$ at the bottom. To avoid instability at high latitudes a simple symmetric finite impulse filter was applied in both hemispheres beyond $55^{\circ}$. Realistic bottom topography was used as much as possible within the limits of grid resolution, including nine islands and a rather realistic Indonesian archipelago.

Horizontal eddy viscosity $A_{M}$ and diffusivity $A_{H}$ were $1 \times 10^{8} \mathrm{~cm}^{2} \mathrm{~s}^{-1}$ and $1 \times 10^{7} \mathrm{~cm}^{2} \mathrm{~s}^{-1}$, respectively. Fluxes of heat and salinity were fixed to zero at the bottom and at the side wall. Bottom friction was given by $C_{D}|\mathbf{u}| \mathbf{u}$ with $C_{D}=0.0025$, and a no-slip boundary condition was applied at the sidewall.

Vertical eddy viscosity $K_{M}$ and diffusivity $K_{H}$ were given by 1 and $0.2 \mathrm{~cm}^{2} \mathrm{~s}^{-1}$, respectively, in the case of constant vertical mixing. Convection is implemented by applying very large eddy diffusivity $\left(K_{H}=10^{5} \mathrm{~cm}^{2}\right.$ $\mathrm{s}^{-1}$ ), whenever unstable.

In the case with the Pacanowski and Philander scheme (1981) $K_{M}$ and $K_{H}$ were given by

$$
\begin{aligned}
& K_{M}=\frac{K_{0}}{(1+a \mathrm{Ri})^{2}}+K_{M 0}, \\
& K_{H}=\frac{K_{M}}{1+a \mathrm{Ri}}+K_{H 0},
\end{aligned}
$$

where the empirical constants were given by $a=5, K_{0}$ $=50 \mathrm{~cm}^{2} \mathrm{~s}^{-1}, K_{M 0}=0.0134 \mathrm{~cm}^{2} \mathrm{~s}^{-1}$, and $K_{H 0}=0.001$ $34 \mathrm{~cm}^{2} \mathrm{~s}^{-1}$. Here Ri is the Richardson number

$$
\mathrm{Ri}=\frac{N^{2}}{(\partial u / \partial z)^{2}+(\partial v / \partial z)^{2}},
$$

where $N$ is the Brunt-Väisälä frequency.

The model was started from a state of rest, with annual mean temperature and salinity distributions by Levitus (1982), and forced by Hellerman and Rosenstein (1983) wind stress climatology. To prescribe the heat flux at the surface the reanalysis data from the National Centers for Environmental Prediction (NCEP) were used. Meanwhile, optimally interpolated SST (OISST) (Reynolds and Smith 1994) data were used for SST instead of Levitus data for more accurate prescription of the surface boundary condition. For the surface forcing the monthly mean data were used with a linear interpolation at each time step. Heat flux, given by $Q$ in (3), was set to zero when the SST is below $-2^{\circ} \mathrm{C}$, assuming that the sea surface is covered by ice. Surface salinity was restored to the climatological value of Levitus (1982) with a restoring timescale of 30 days 
(a) EXP AO

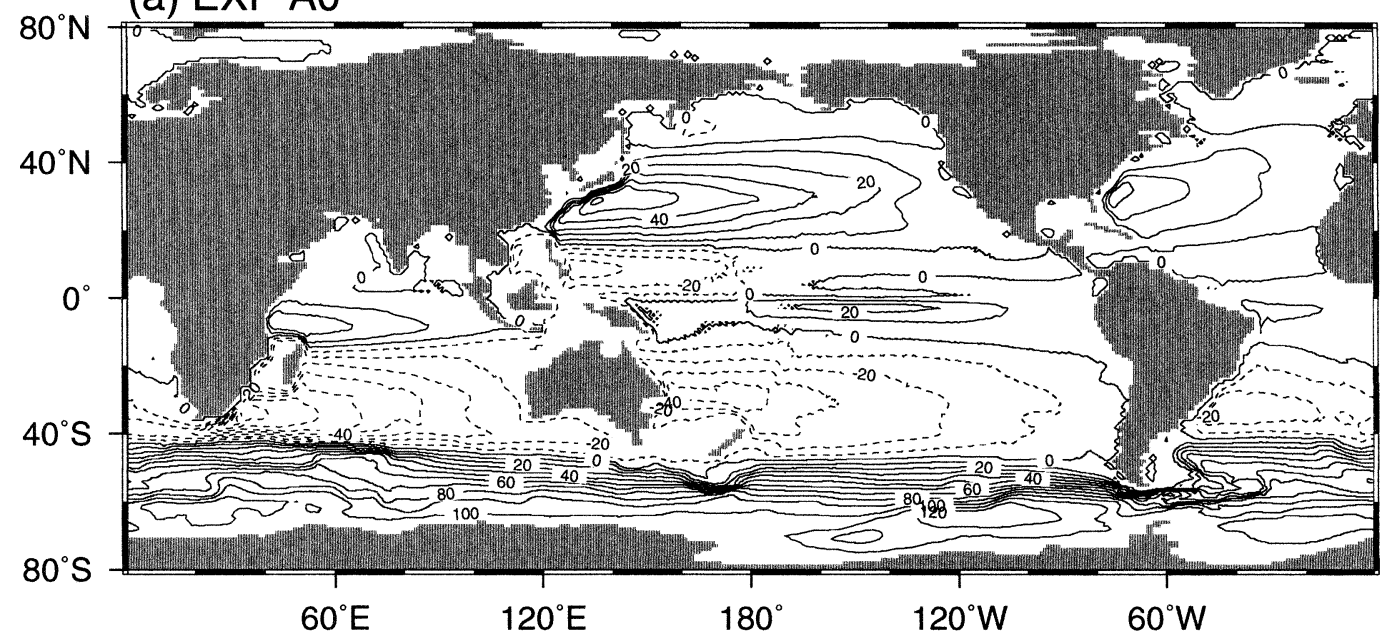

(b) EXP A1

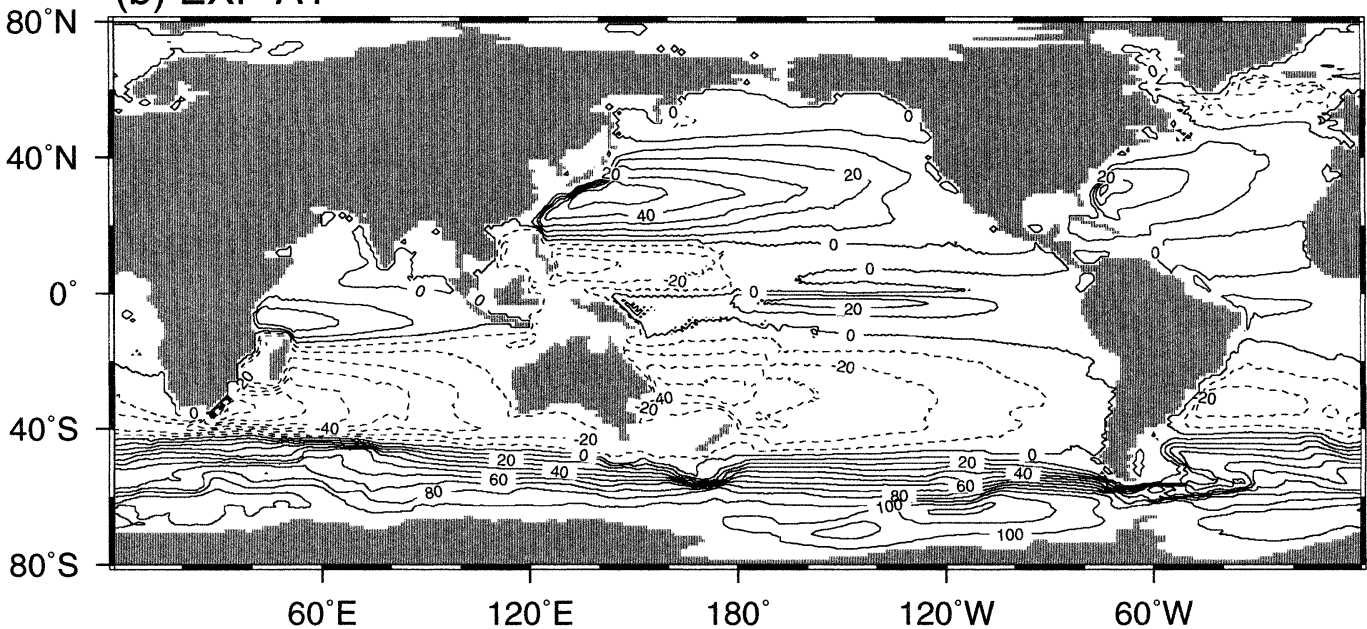

FIG. 1. Annual mean volume transport streamfunction (Sv): (a) EXP A0 and (b) EXP A1.

throughout all experiments. The model was integrated for 24 years, which is believed to be sufficient for examining the changes in the heat flux and temperature in the upper ocean (Sterl and Kattenberg 1994).

\section{b. OMLM}

Recent measurements of the microstructure of the oceanic boundary layer from various field experiments have revealed that dynamic processes of the oceanic boundary layer is fundamentally different from that of the atmospheric boundary layer (see, e.g., Drennan et al. 1996; Terray et al. 1996). Particularly they observed that turbulent kinetic energy (TKE) is enhanced remarkably near the sea surface, unlike near the rigid boundary of the atmospheric boundary layer. A high level of TKE near the sea surface helps to maintain the well-mixed layer in the upper ocean. This also makes downward flux of TKE important in the TKE budget of the upper mixed layer, while rendering TKE production by the mean velocity shear relatively unimportant (Noh 1996).

Noh and Kim (1999) recently developed a new OMLM, taking these observational evidences into consideration. The model is a second-order turbulence closure model using eddy diffusivity, but it produces a well-mixed layer even under the stabilizing heat flux, consistent with the observation and the bulk-type OMLMs (i.e., Kraus and Turner 1977), whereas most other OMLMs using eddy diffusivity lead to strong stratification and shear near the surface (i.e., Mellor and Yamada 1982).

The model calculates the vertical eddy viscosity $K_{M}$, the eddy diffusivity of temperature and salinity $K_{H}$, and the eddy diffusivity of turbulent kinetic energy $K_{E}$ by

$$
\begin{aligned}
K_{M} & =S_{M} q l, \\
K_{H} & =S_{H} q l, \\
K_{E} & =S_{E} q l,
\end{aligned}
$$


(a) annual simulation - observation

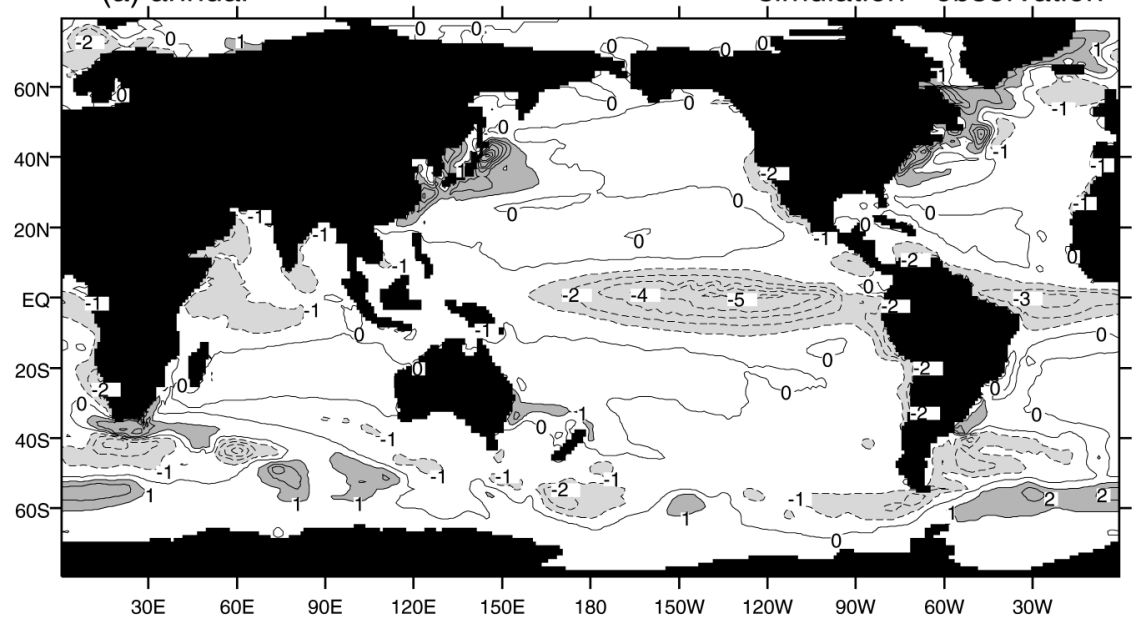

(b) January
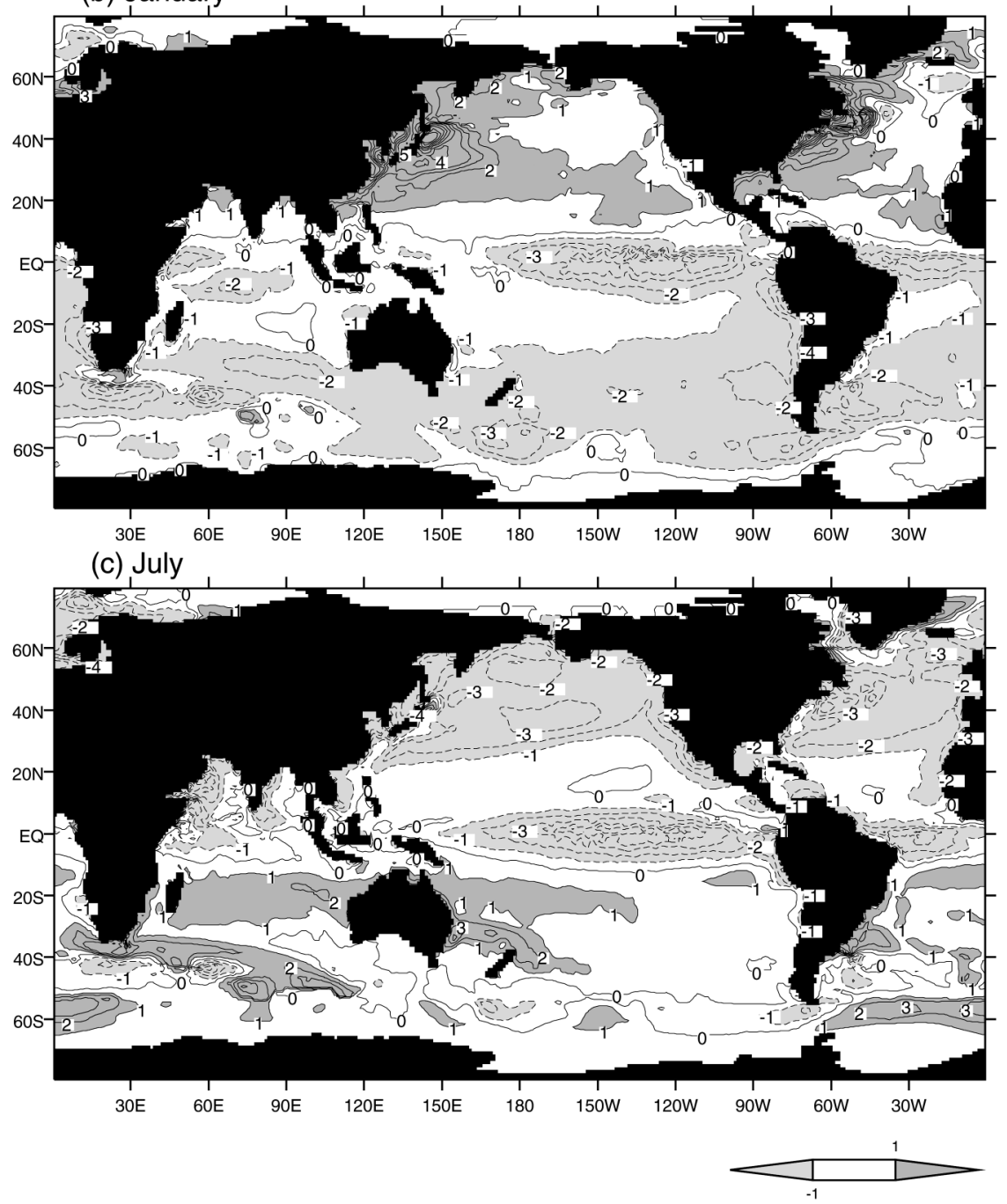

FIG. 2. Distributions of the SST anomaly $\left({ }^{\circ} \mathrm{C}\right.$ ) for EXP A0: (a) annual mean, (b) Jan, and (c) Jul. Contour interval is $1^{\circ} \mathrm{C}$, and solid and dashed lines represent positive and negative anomalies, respectively. Areas with an SST anomaly larger than $1^{\circ} \mathrm{C}$ are shaded. 
(a) annual simulation - observation

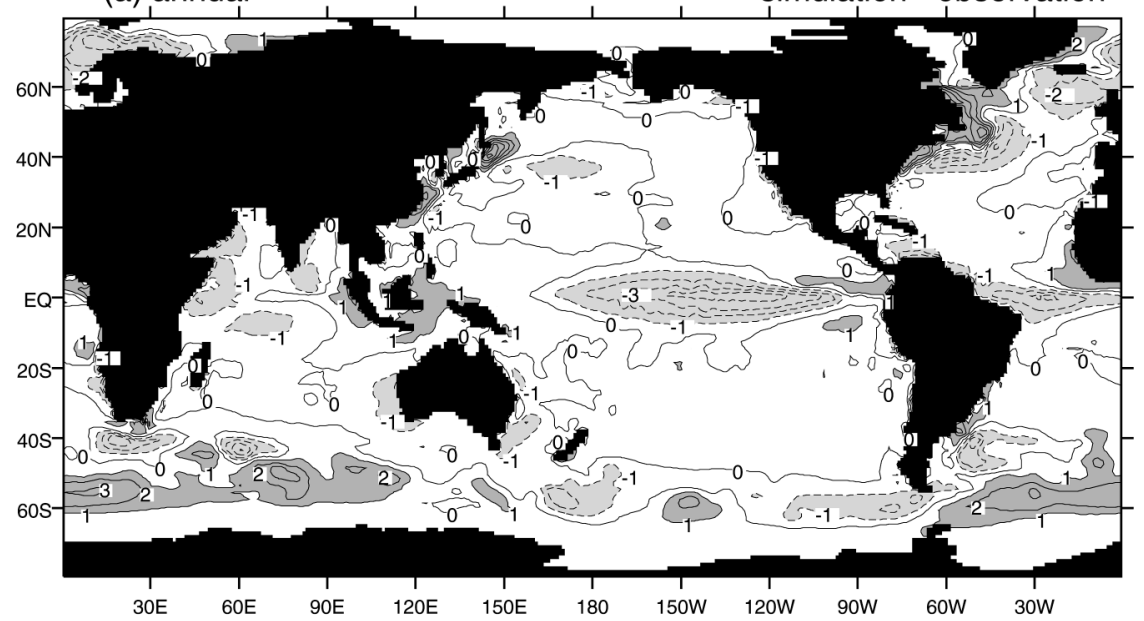

(b) January

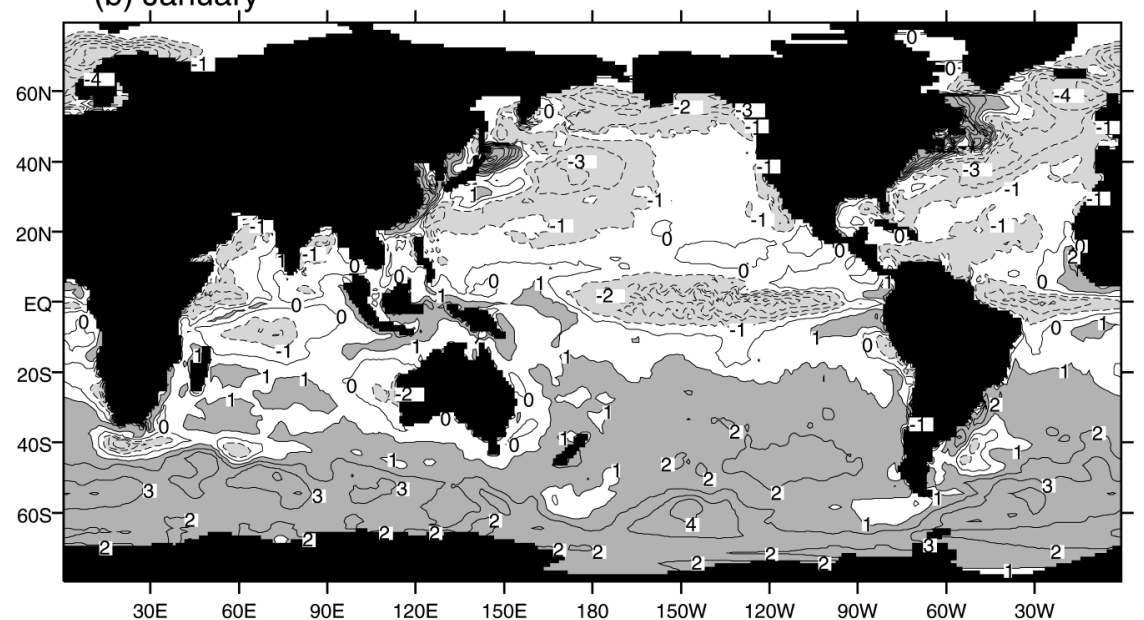

(c) July
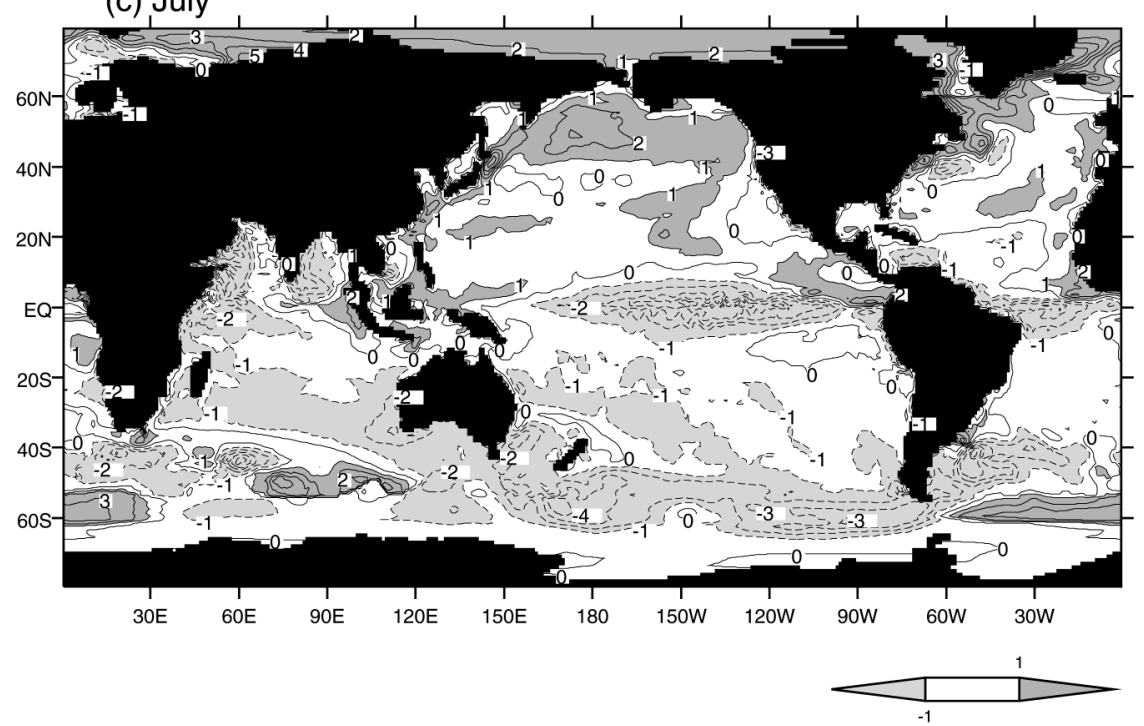

FIG. 3. As in Fig. 2 but for EXP A1. 
(a) northern hemisphere
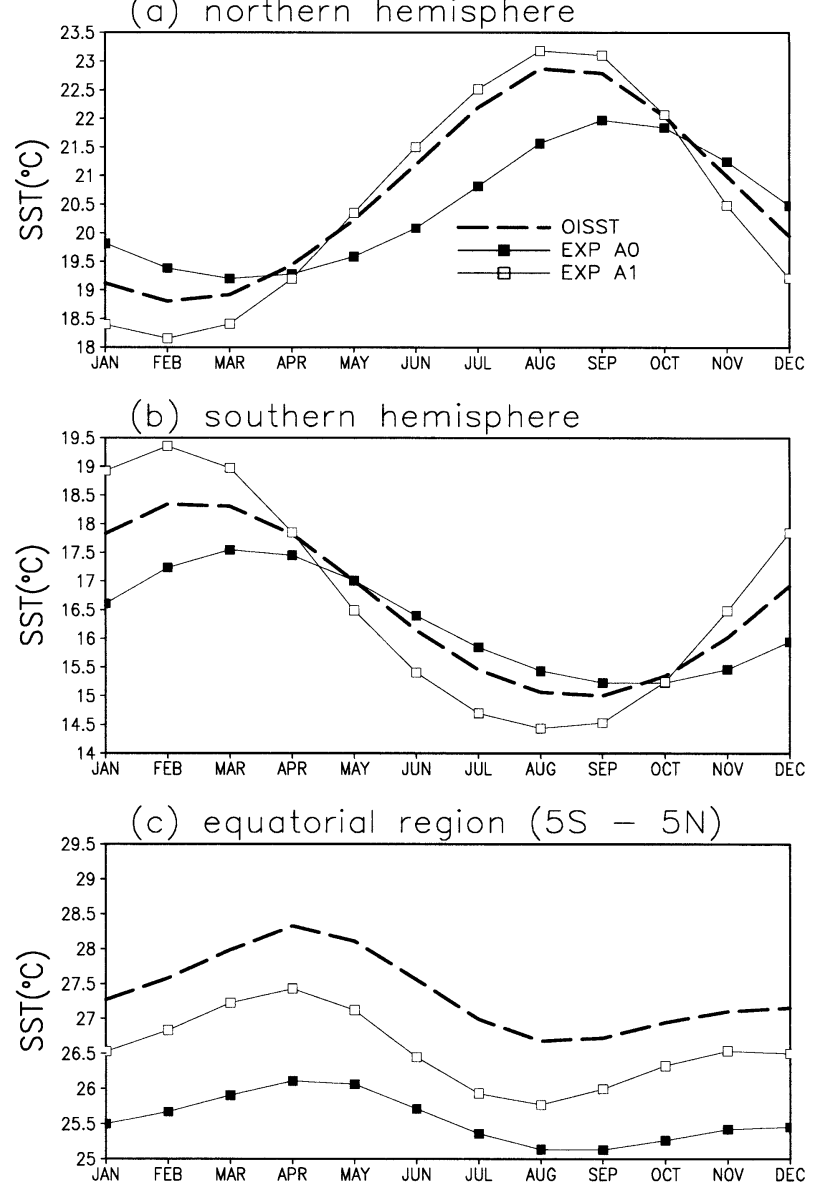

FIG. 4. Seasonal variations of the mean SST $\left({ }^{\circ} \mathrm{C}\right.$ ) (climatology, EXP A0, EXP A1): (a) Northern Hemisphere, (b) Southern Hemisphere, and (c) equatorial region $\left(5^{\circ} \mathrm{S}-5^{\circ} \mathrm{N}\right)$. OISST represents Optimally Interpolated SST data (Reynolds and Smith 1994).

where $q^{2} / 2(=E)$ is TKE, $l$ is the length scale of turbulence, and $S_{M}, S_{H}$, and $S_{E}$ are empirical constants.

Turbulent kinetic energy $E$ is obtained from

$$
\begin{aligned}
\frac{\partial E}{\partial t}= & \frac{\partial}{\partial z}\left(K_{E} \frac{\partial E}{\partial z}\right)+K_{M}\left[\left(\frac{\partial u}{\partial z}\right)^{2}+\left(\frac{\partial v}{\partial z}\right)^{2}\right] \\
& -K_{H} \frac{g}{\rho_{0}} \frac{\partial \rho}{\partial z}-\varepsilon
\end{aligned}
$$

if horizontal advection and diffusion are neglected. Here $g, \rho_{0}$, and $\rho$ represent the gravitational acceleration and the reference and local density, respectively. The dissipation rate $\varepsilon$ is calculated by

$$
\varepsilon=C_{\varepsilon} q^{3} / l \text {. }
$$

Equations (8)-(12) are typical for the second-order turbulence closure model. The coefficients are taken as the same as in Mellor and Yamada (1982) in a homogeneous fluid: $S_{M}=0.39\left(\equiv S_{M 0}\right), S_{M} / S_{H}=0.8$, and $S_{M} / S_{E}=1.95$, and $C_{\varepsilon}=0.06\left(\equiv C_{\varepsilon 0}\right)$.

However, the model is quite different from the Mellor

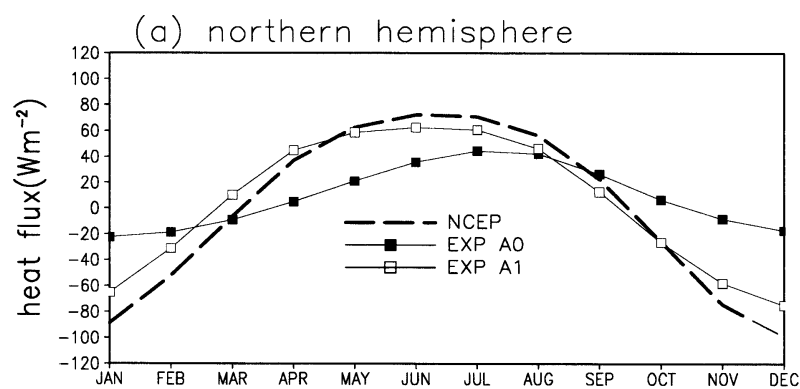

(b) southern hemisphere
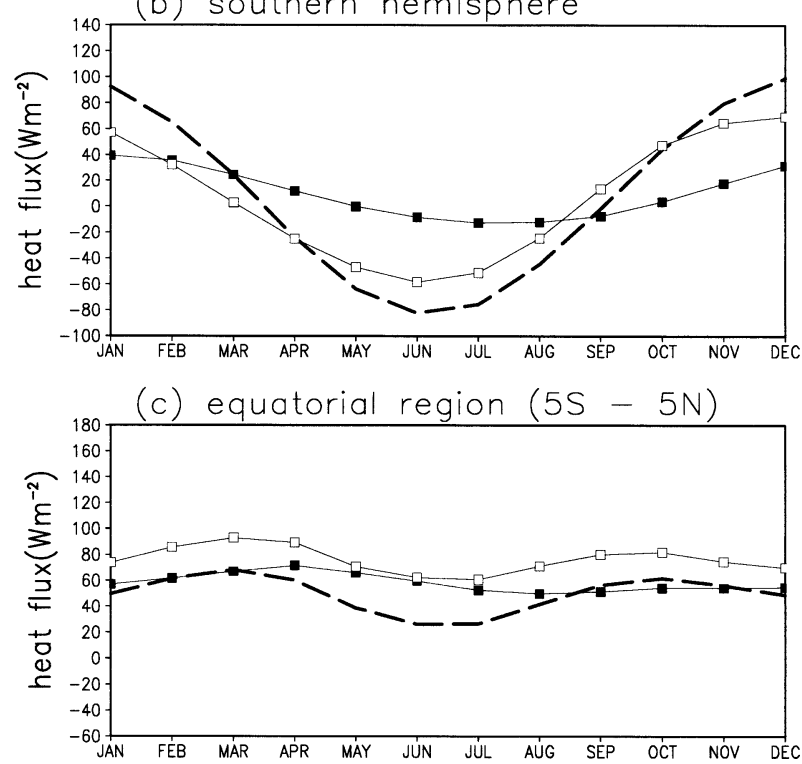

FIG. 5. As in Fig. 4 but for mean heat flux $\left(\mathrm{W} \mathrm{m}^{-2}\right)$.

and Yamada model in the parameterizations of the surface forcing and of the effects of stratification. The boundary condition for TKE is given by

$$
K_{E} \frac{\partial E}{\partial z}=m u_{*}^{3},
$$

where $u_{*}$ is the frictional velocity due to wind stress. Meanwhile, the length scale $l$ is given by

$$
l=\frac{\kappa\left(z+z_{0}\right)}{1+\kappa\left(z+z_{0}\right) / h},
$$

where $h$ is the depth of a mixed layer, $\kappa$ the von Kármán constant $(=0.4)$, and $z_{0}$ the roughness length scale at the surface.

Based on Craig and Banner's analysis (1994) on recent observational data of the upper ocean, Noh and Kim (1999) assumed the values $m=100$ and $z_{0}=1$ $\mathrm{m}$ for (13) and (14). These values characterize the intensive mixing near the sea surface, as mentioned above. In this case the relevant Richardson number, which is used to represent the effects of stratification, should be determined in terms of TKE itself rather than the mean velocity shear because the TKE flux plays an important 

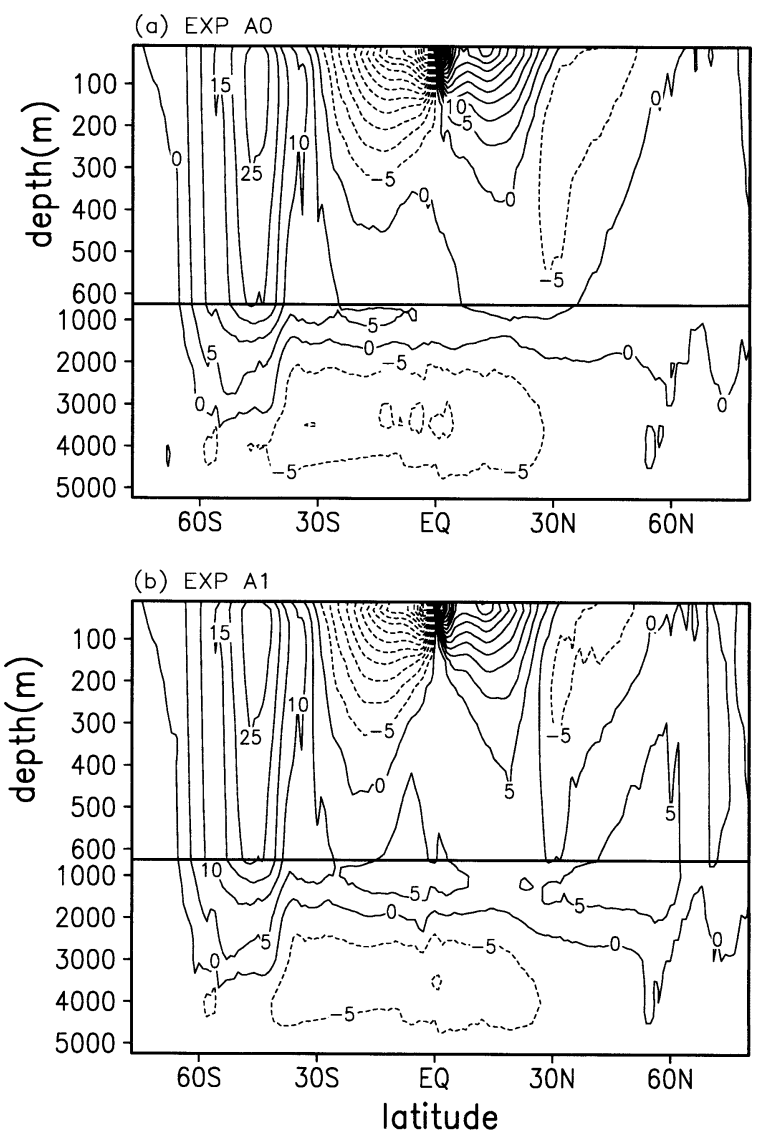

FIG. 6. Meridional overturning streamfunction (Sv): (a) EXP A0 and (b) EXP A1.

role in TKE production. Therefore, the TKE Richardson number defined by

$$
R_{t}=(N l / q)^{2}
$$

must be used instead of Ri given by (7).

In this case we can parameterize the effects of stratification as

$$
\begin{aligned}
& S_{M} / S_{M 0}=\left(1+\alpha R_{t}\right)^{-1 / 2}, \\
& C_{\varepsilon} / C_{\varepsilon 0}=\left(1+\alpha R_{t}\right)^{-1 / 2},
\end{aligned}
$$

similar to Wyngaard (1985), where $\alpha$ is an empirical constant. Meanwhile, the proportionality of $S_{H}$ and $S_{E}$ to $S_{M}$ is maintained.

A uniform mixed layer is maintained during convection, which means $K_{M}=K_{H}=\infty$ whenever $R_{t}<0$. However, the vertical transfer of TKE is assumed to be unaffected by convection, that is, $K_{E}=K_{E}\left(R_{t}=0\right)$, based on the scaling analysis. See Noh and Kim (1999) for more detailed description of the model.

The resultant model was successful for the first time in predicting correctly the evolution of both the vertical profiles of temperature and the turbulence structure of the mixed layer, as well as the SST, that was the main concern in the previous results (Noh and Kim 1999).
The new OMLM was also shown to realistically simulate the formation of a diurnal thermocline, which remains one of the most difficult problems in most OMLMs (Noh 1996). However, the model was developed mainly for prediction of the diurnal variation of the upper ocean. Therefore, some modifications are necessary so as to be applied to the seasonal variation of the deeper ocean as in the OGCM.

First, we expect that vertical mixing during convection into the deeper ocean cannot occur instantaneously but over a certain timescale with the corresponding finite values of $K_{H}$. We assume the eddy diffusivity during convection as $K_{H}=10^{5} \mathrm{~cm}^{2} \mathrm{~s}^{-1}$, following the suggestion by Klinger et al. (1996). It was reported, however, that the results are insensitive to the value of $K_{H}$ during convection as long as they are within the range of $10^{4}-10^{7} \mathrm{~cm}^{2} \mathrm{~s}^{-1}$ (Hirst and Cai 1994).

Meanwhile, Killworth (1989) suggested that it is not desirable to force the vertical mixing of momentum during convection in the OGCM since geostrophic adjustment tends to make the velocity field vertically uniform for large-scale flows. So we assume that eddy viscosity $K_{M}$, as well as $K_{E}$, maintains the value of a homogeneous fluid, unaffected by convection. It was also observed, however, by Killworth that the results are largely independent of whether momentum is mixed or not during convection.

Noh and Kim (1999) evaluated the empirical constant $\alpha$ as $\alpha \simeq 120$ in (16) and (17). However, the vertical resolution in that case was $1 \mathrm{~m}$, whereas it is larger than $20 \mathrm{~m}$ in the present case. We expect that the determination of the values of $N$, and thus $R_{t}$ (and also $\mathrm{Ri}$ ), is affected by the vertical resolution of the model. This will be particularly true near the thermocline where the effects of stratification play a critical role. This makes it necessary to reevaluate $\alpha$. The appropriate value of $\alpha$ was estimated to be $\alpha \simeq 1000$ from the analysis of the present OGCM results.

Turbulence generated at the surface cannot be transferred below the mixed layer (Noh 1996), and the sources of turbulence below the mixed layer are fundamentally different from those within the mixed layer. There are various sources of mixing below the mixed layer: for example, internal wave breaking, vertical shear, and double diffusion. Although various parameterizations could be suggested to represent the mixing owing to the afore-mentioned mechanisms (Large et al. 1994; Toole 1998), there still remains extreme uncertainty regarding how important they are and how they should be parameterized. Moreover, the previously mentioned sources of turbulence are related to small-scale phenomena that require fine-scale resolution for meaningful parameterization, whereas the vertical resolution of the OGCM is usually very poor in the deep ocean, having a typical vertical grid size of a few hundred meters.

Therefore, in this model we assume that the eddy viscosity $K_{M B}$ and eddy diffusivity $K_{H B}$ below the mixed layer can be roughly estimated as 1 and $0.1 \mathrm{~cm}^{2} \mathrm{~s}^{-1}$, 
(a) annual

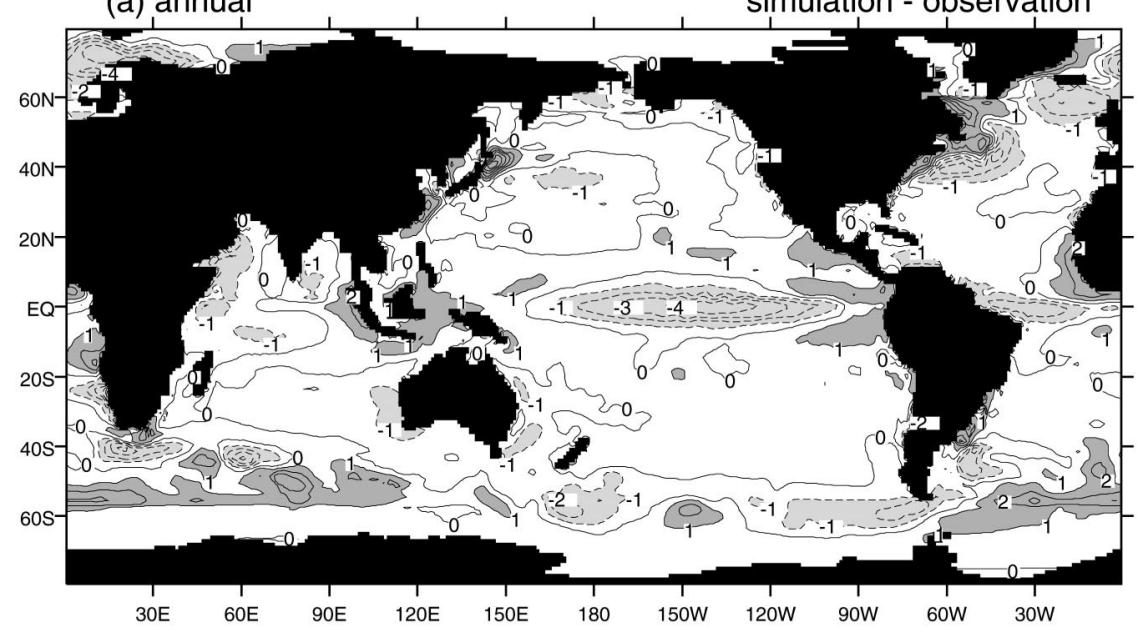

(b) January

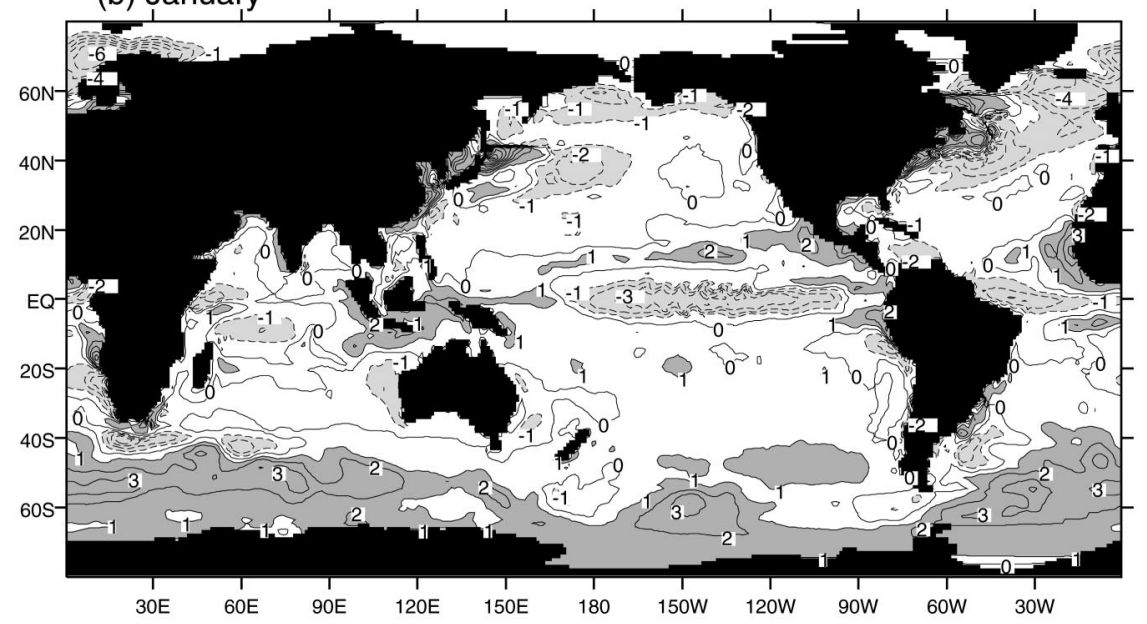

(c) July

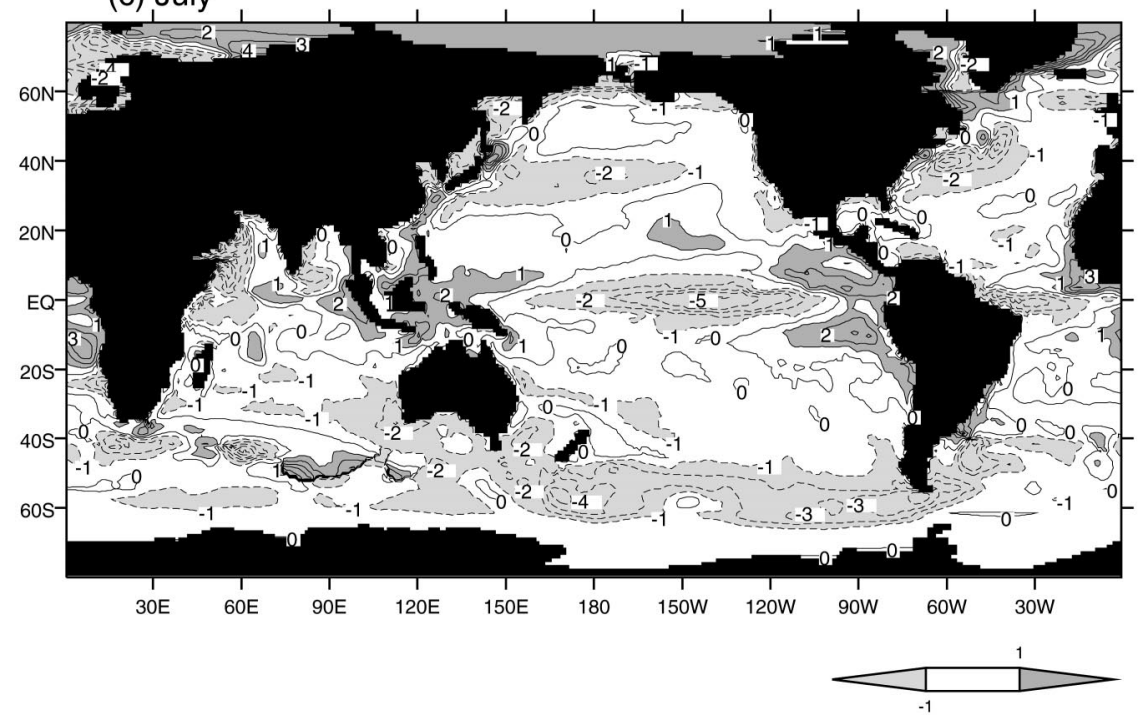

FIG. 7. Distributions of the SST anomaly $\left({ }^{\circ} \mathrm{C}\right)$ for EXP B1: (a) annual mean, (b) Jan, and (c) Jul. The contour interval is $1^{\circ} \mathrm{C}$, and solid and dashed lines represent positive and negative anomalies, respectively. Areas with an SST anomaly larger than $1^{\circ} \mathrm{C}$ are shaded. 
(a) annual simulation - observation

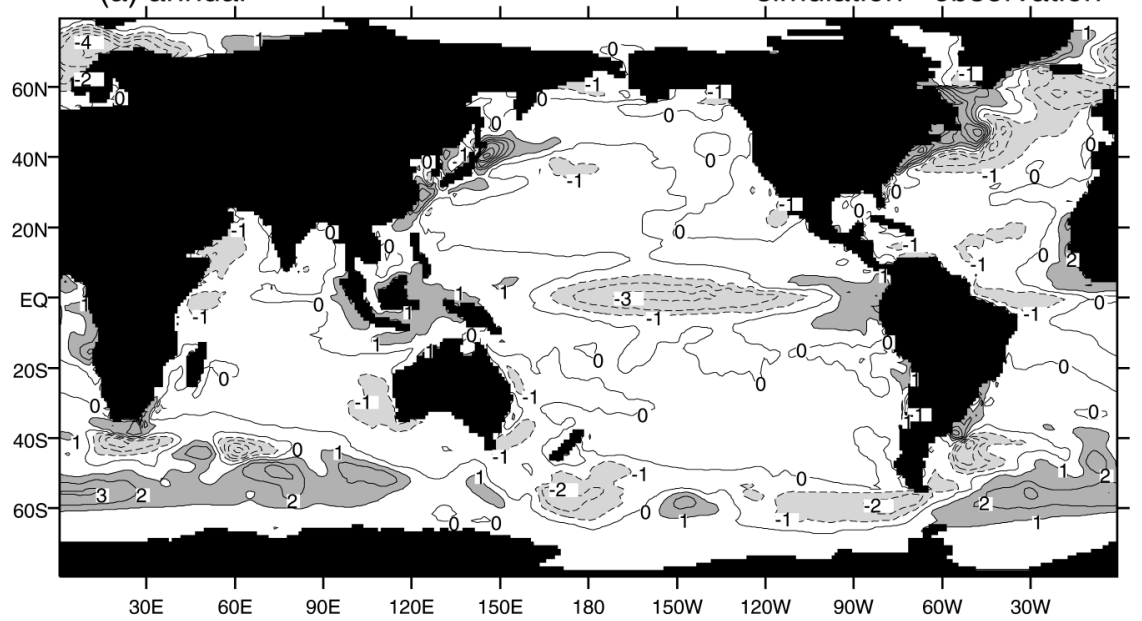

(b) January

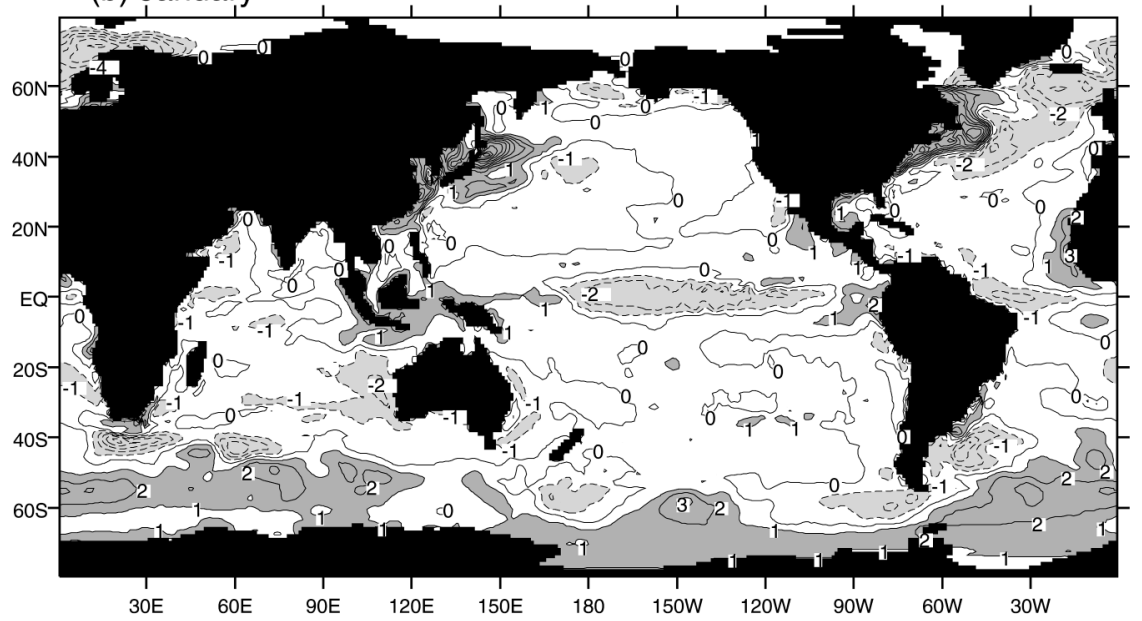

(c) July
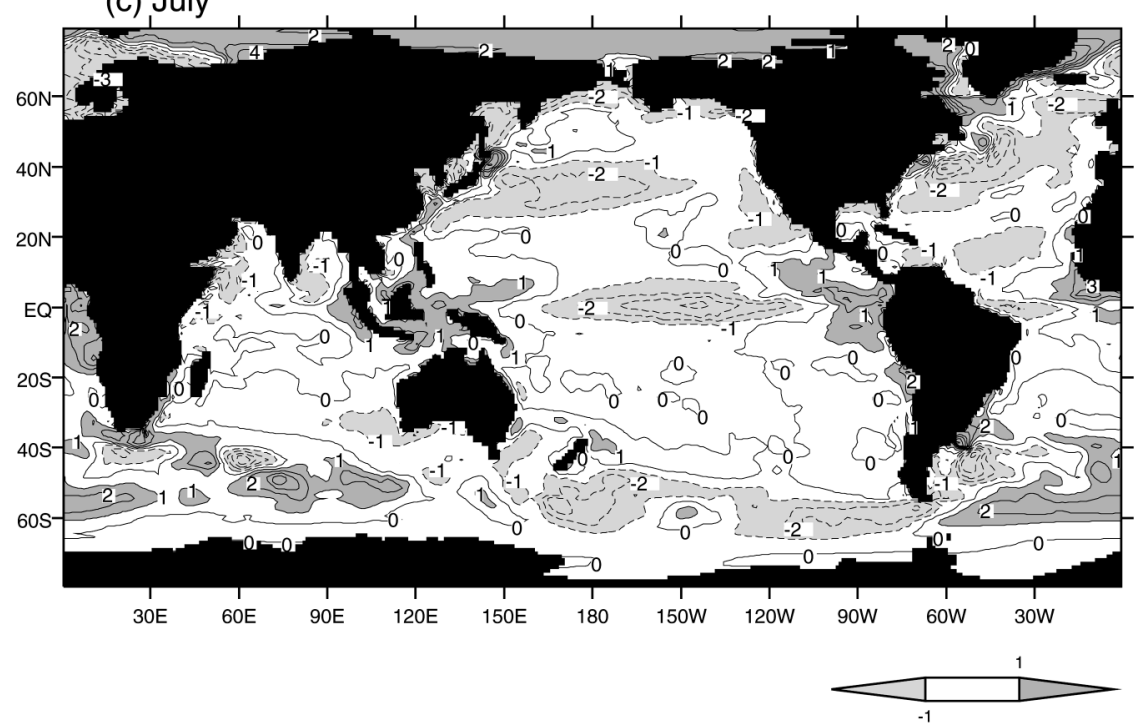

FIG. 8. As in Fig. 7 but for EXP C1. 
(a) northern hemisphere

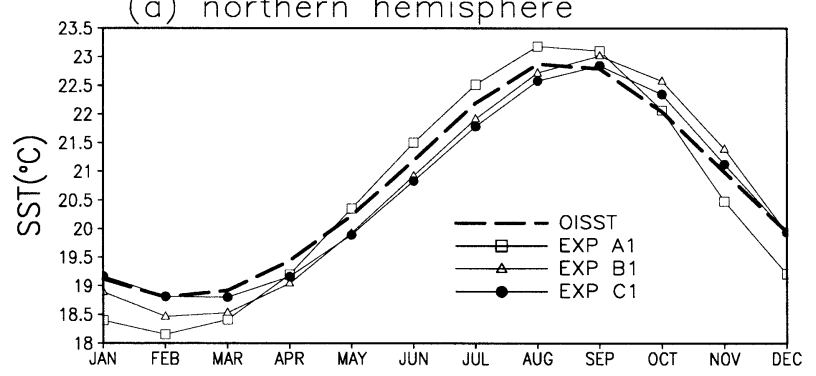

(b) southern hemisphere
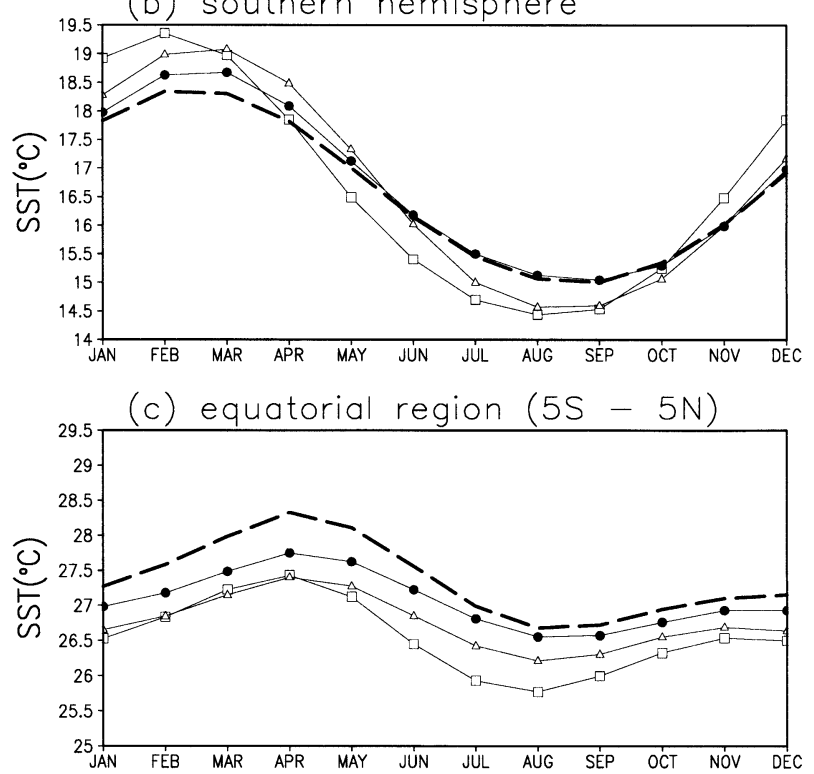

FIG. 9. Seasonal variations of the mean SST $\left({ }^{\circ} \mathrm{C}\right.$ ) (climatology, EXP A1, EXP B1, EXP C1): (a) Northern Hemisphere, (b) Southern Hemisphere, and (c) equatorial region $\left(5^{\circ} \mathrm{S}-5^{\circ} \mathrm{N}\right)$.

respectively, as the simplest way of representing subsurface mixing under this extremely uncertain situation. These values follow the estimation of the mixing due to internal wave breaking given by Large et al. (1994) and Toole (1998), estimated from the observational data (Gregg 1989; Peters et al. 1988; Ledwell et al. 1993) and the Garrett-Munk (1975) internal wave model. On the other hand, the magnitudes of mixing owing to vertical shear and double diffusion are expected to be not larger than that by internal wave breaking, although it is extremely difficult to estimate them (Toole 1998). It is thus assumed that the contributions to mixing from these mechanisms are included in the above estimations of $K_{M B}$ and $K_{H B}$.

Noh (1996) suggested that the mixed layer depth can be represented most appropriately by the depth where the vertical mixing decreases to a certain level. Accordingly, in the present model the definition of mixed layer depth $h$ is given by the depth at which the calculated eddy viscosity $K_{H}$ decreases with depth to the value of $K_{H B}$. For depths deeper than $h$, we simply put $K_{M}=K_{M B}$ and $K_{H}=K_{H B}$.
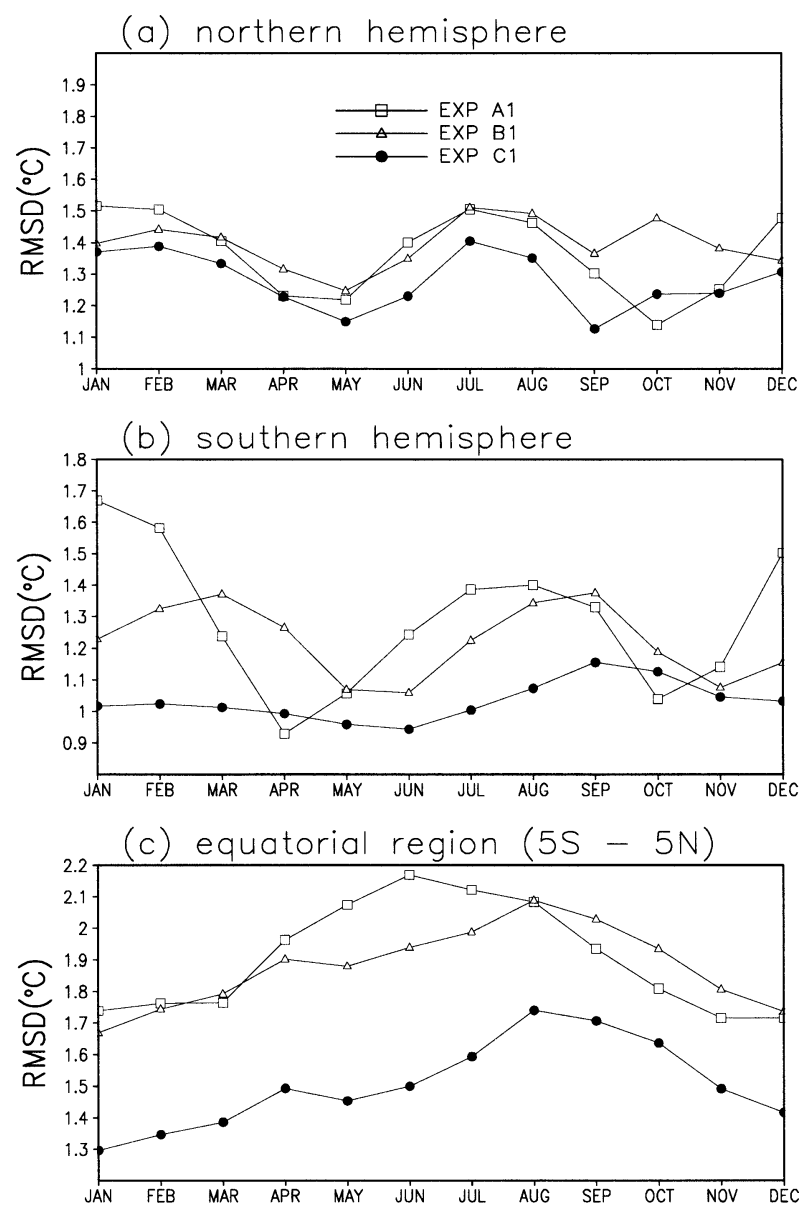

FIG. 10. As in Fig. 9 but for the rms of SST anomaly $\left({ }^{\circ} \mathrm{C}\right)$ (EXP A1, EXP B1, EXP C1).

As described above, the present OMLM actually prescribes the vertical mixing over the whole depth of the ocean as well as within the mixed layer, although most concerns focus on the latter. Therefore, the present OMLM can be also referred to as the vertical mixing scheme, as are the cases of other OMLMs (Rosati and Miyakoda 1988; Large et al. 1997).

\section{c. Experiments}

Numerical experiments with different combinations of the mixed layer process and surface thermal forcing were carried out in the following three steps. First, we considered the effects of different surface boundary con-

TABLE 1. Rms difference of the simulated regional mean SST $\left(\mathrm{C}^{\circ}\right)$ from the observed data in the Northern Hemisphere (NH), the Southern Hemisphere (SH), and the equatorial region (EQ).

\begin{tabular}{cccc}
\hline \hline Expt & $\mathrm{NH}$ & $\mathrm{SH}$ & $\mathrm{EQ}$ \\
\hline EXP A1 & 0.45 & 0.69 & 0.83 \\
EXP B1 & 0.32 & 0.46 & 0.64 \\
EXP C1 & 0.24 & 0.17 & 0.34 \\
\hline
\end{tabular}


TABLE 2. As in Table 1 but for the regional mean of the rms difference of the simulated SST $\left(\mathrm{C}^{\circ}\right)$ from the observed data.

\begin{tabular}{cccc}
\hline \hline Expt & $\mathrm{NH}$ & $\mathrm{SH}$ & EQ \\
\hline EXP A1 & 1.37 & 1.29 & 1.90 \\
EXP B1 & 1.39 & 1.22 & 1.88 \\
EXP C1 & 1.28 & 1.03 & 1.50 \\
\hline
\end{tabular}

ditions for temperature using the OGCM with constant vertical mixing coefficients, that is, the restoring boundary condition (EXP A0) and the combined boundary condition (EXP A1). In both cases the restoring timescale $\tau$ was fixed to 30 days. The results were analyzed from the perspective of the realizations of the observed SST and heat flux.

Second, we carried out the experiments with OGCMs under the same combined boundary condition but with different vertical mixing schemes. We tried the vertical mixing schemes by Pacanowski and Philander (1981) and the new OMLM explained in the previous section, referred to as EXP B1 and EXP C1, respectively. By comparing the results from EXP B1 and EXP C1 together with those from EXP A1 we investigated the effects of the mixed layer process on the results of the OGCM, with major emphasis on the upper ocean.

Note that, when the restoring boundary condition is used in the OGCM, the more accurate prediction of SST means the poorer prediction of surface heat flux, which makes it impossible to compare the performance of the OMLM. On the other hand, in the combined boundary condition the prediction of more accurate SST coincides with more realistic surface heat flux, and thus illustrates the better performance of the OGCM.

Finally, once we realized that the new OMLM performs well, we repeated EXP C1 but with a restoring timescale increased to a more realistic value $(\tau=60$ days), referred to as EXP C2. From the comparison between EXP C1 and EXP C2 we investigated how the increased restoring time affects the general performance of the model. Note that the OMLM should perform well under the natural feedback between the atmosphere and the ocean if it really represents the mixed layer process properly.

\section{Results}

\section{a. Comparison between the restoring and combined surface thermal forcing (EXPs AO and A1)}

Figure 1 shows the annual mean volume transport streamfunction obtained from EXPs $\mathrm{A} 0$ and $\mathrm{A} 1$, respectively. Both cases are similar to each other and reproduce the general features of the global circulation of the ocean satisfactorily regardless of the difference in the surface boundary condition of temperature. This confirms that the global circulation is driven primarily by wind stress. In both cases the intensity of western boundary currents are somewhat weaker and their sep-
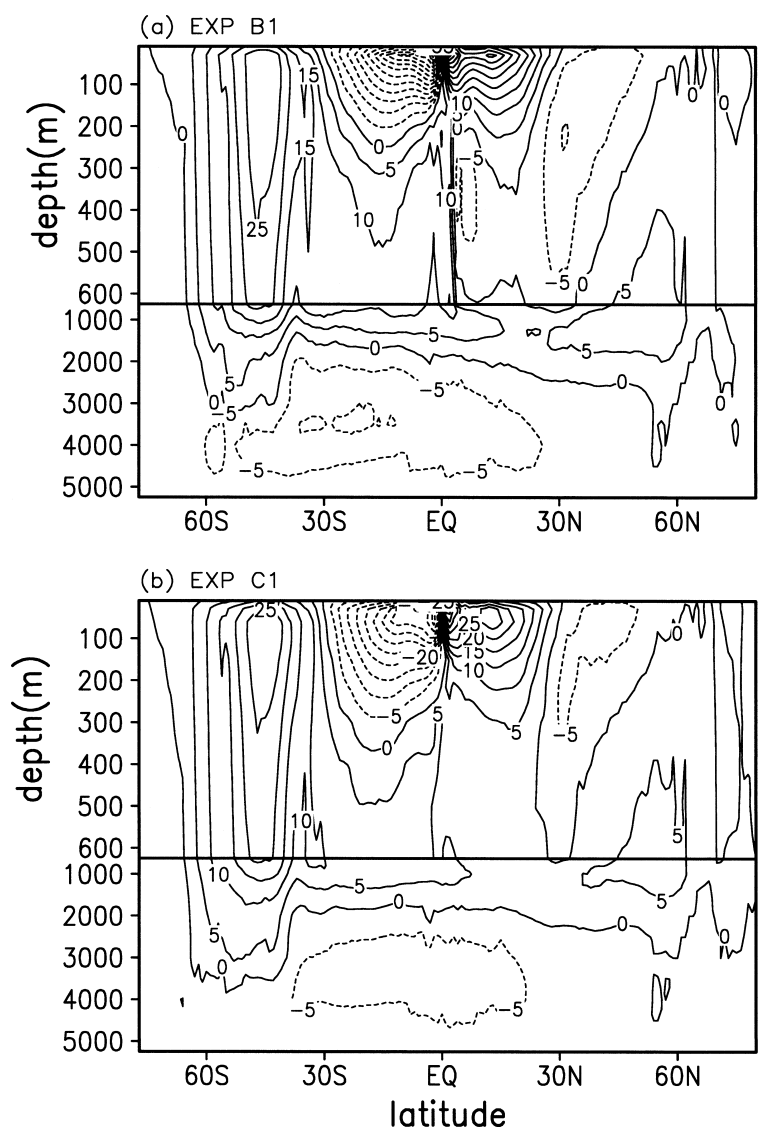

FIG. 11. Meridional overturning streamfunction (Sv): (a) EXP B1 and (b) EXP C1.

aration points are located rather northward compared to the observation, probably due to insufficient grid resolution, as in the cases of most other OGCMs (see, e.g., Haidvogel and Bryan 1992). Nevertheless, the maximum annual mean transports of the Gulf Stream and the Kuroshio, given by approximately $30-40 \mathrm{~Sv}$ and $50-60 \mathrm{~Sv}\left(\mathrm{~Sv} \equiv 10^{6} \mathrm{~m}^{3} \mathrm{~s}^{-1}\right)$ are in agreement with the high-resolution simulation results (Semtner and Chervin 1992) and other observation data (Tomczak and Godfrey 1994). The transports of the Antarctic Circumpolar Current (ACC) through Drake Passage and the Indonesian Throughflow are approximately $100-110 \mathrm{~Sv}$ and 10 $20 \mathrm{~Sv}$, respectively, and are also within the reasonable range of observational estimates (Fieux et al. 1994; Godfrey et al. 1993; Nowlin and Klinck 1986).

The only noticeable difference is observed in the high-latitude region where deep convection occurs. The convective pattern and the consequential anticlockwise circulation in the northern Atlantic appear in EXP A1, but not in EXP A0, which may be associated with the fact that convection is suppressed by the restoring boundary condition (Mikolajewicz and Maier-Reimer 1994; Cai and Chu 1996; Toggweiler et al. 1989). It is also observed that the ACC is slightly stronger in EXP A0, whereas the Gulf Stream is slightly stronger in EXP 


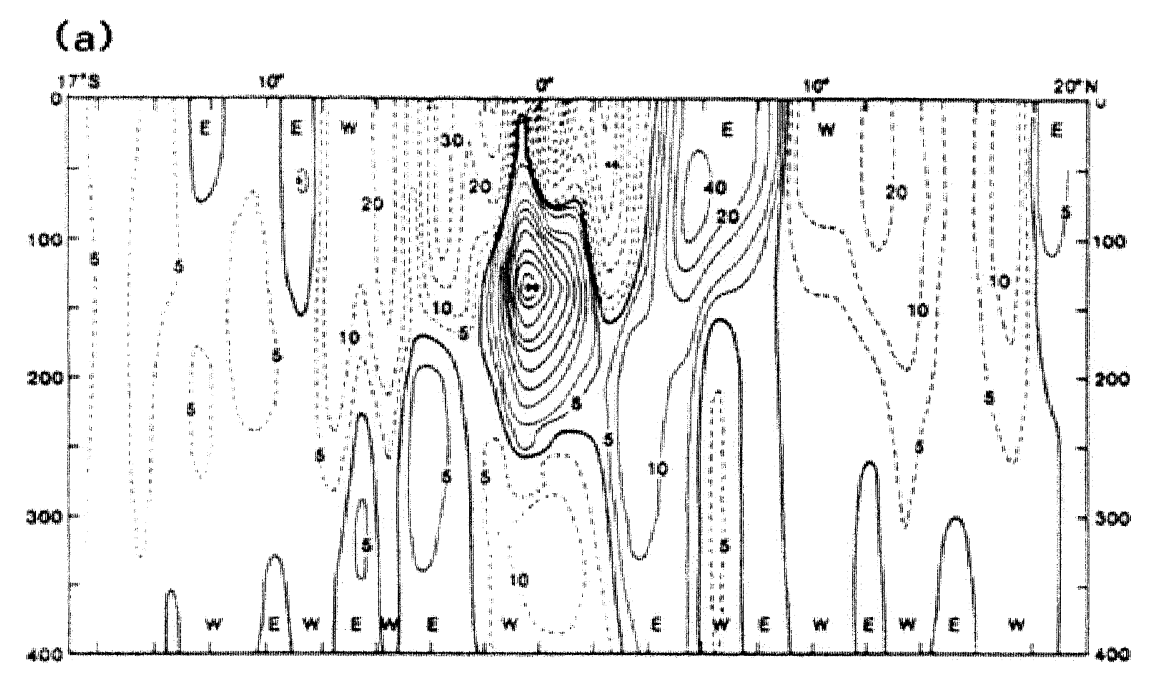

FIG. 12. Cross sections of the annual-mean zonal velocity at the equator and $155^{\circ} \mathrm{W}$ : (a) climatology [Hawaii-Tahiti Shuttle Experiment (Wyrtki and Kilonsky 1984)], (b) EXP A1, (c) EXP B1, and (d) EXP C1.

A1. The differences in OGCM results between two different surface forcing methods mentioned above are also in agreement with the results by Maltrud et al. (1998), who used higher-resolution grids and higher-frequency data.

It should be mentioned, however, that the circulation of the deep ocean is still controlled by the initial $T, S$ distributions given by the observed data in the present simulation. Therefore, we expect that the volume transport streamfunction of Fig. 1 and the meridional overturning streamfunction, given below by Fig. 5, are still affected by the initial $T, S$ distributions. Nevertheless, they still serve effectively to demonstrate the effects of surface forcing and the mixed layer process because the circulations of the deep ocean due to the initial $T, S$ distributions remain equivalent in any case.

Figures 2 and 3 show the global distributions of SST anomaly from the observed distribution, for the cases of the annual mean, January and July, from EXPs A0 and A1. The significant underestimation of SST in the equatorial ocean is observed in both cases. This is very common in most OGCMs and is due to the too strong South Equatorial Current (SEC) and upwelling. We will discuss this again in the next section. The underestimation of SST in the equatorial ocean is somewhat improved in EXP A1, mainly because larger heat flux is applied in that case (see also Fig. 4).

Significant SST anomalies are also found in both cases in the regions where the simulated circulation deviates from the real circulation, such as the separation points of the western boundary currents. For example, the simulated Gulf Stream, which is too broad and overshoots beyond the separation point, causes the dipole SST anomaly, as pointed out by Sterl and Kattenberg (1994). That is, water along the coast appears too warm and recirculated water over the region of warm water moving northward too cool. The displacement of separation points of the Kuroshio, Brazil, and Agulhas Currents also causes the large SST anomalies in the regions off Japan, Argentina, and South Africa. Meanwhile, a too weak Gulf Stream, which does not extend to the North Sea, causes the negative SST anomaly in the North Sea. A large SST anomaly in the ACC region implies an inaccurate representation of variability of the ACC and Polar Front. Hopefully, these shortcomings can be remedied by more accurate simulation of circulation, possibly with a higher-resolution OGCM.

However, the most striking SST anomaly is observed in the seasonal variation of SST, where the opposite tendency of the SST anomaly appears between two cases. The SST turns out to be too low during summer and too high during winter in EXP A0 (Figs. 2b,c), and vice versa in EXP A1 (Figs. 3b,c). This means that the amplitude of the seasonal cycle of SST is too small in EXP A0, whereas it is too large in EXP A1, as shown in the seasonal variations of the hemispheric mean SST (Fig. 4).

In the case of the restoring boundary condition (EXP A0), the SST is actually "dragged" to the climatological SST and thus results in the reduced amplitude and phase lag of the seasonal variation of SST, as mentioned by Haidvogel and Bryan (1993). On the other hand, overestimation of SST during the warming season in EXP A1 is caused by improper vertical transfer of heat from the surface. Although we can attempt to improve the prediction of SST by increasing the vertical mixing coefficient in this case, this leads to a severely unrealistic vertical structure of temperature, which already suffers from a too deep and diffuse thermocline (Haidvogel and Bryan 1993). During summer too high SST in EXP A1 causes the heat flux to be underestimated, as expected from (3) (see Fig. 5). Consequently, an insufficient amount of heat accu- 

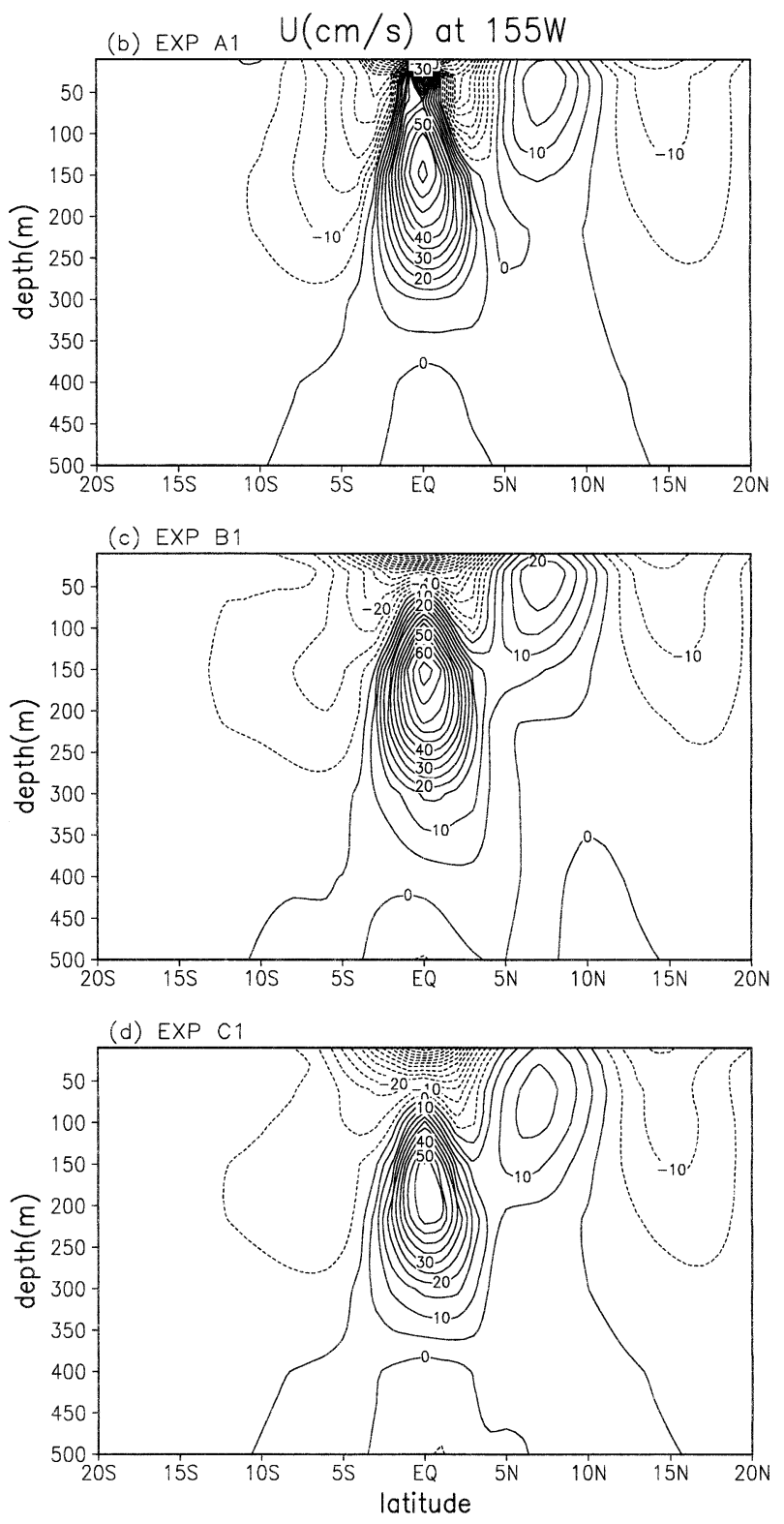

FIG. 12. (Continued)

mulated during summer possibly leads to too low SST under the cooling in winter in Fig. 3.

Figure 5 shows the seasonal cycle of the resultant hemispheric mean heat flux based on the simulated SST in comparison with the climatological heat flux $Q^{*}$. The resultant heat flux is found to be improved in EXP A1, as expected from the fact that the climatological heat flux itself is included in the calculation. Nonetheless, the contribution from the restoring term still remains significantly large, and this suggests that many problems associated with the restoring boundary condition still persist. The experiment with the larger restoring timescale of 60 days aggravates the situation further (not shown) because the simulated SST deviates severely from the observed SST.

As expected from Fig. 5, the increased seasonal cycles of heat flux result in a stronger meridional overturning streamfunction (Fig. 6). Especially the suppression of deep convection in the North Atlantic, as mentioned above, is evidenced clearly in Fig. 6a and it causes the clockwise circulation in the northern thermohaline cell at intermediate depths to be very weak in EXP A0. The situation is improved in EXP A1. Meanwhile, the overall results in Fig. 6 are in good agreement with Semtner and Chervin (1992) and Maltrud et al. (1998), but the thermohaline circulation in the Northern Hemisphere is weaker than that in Large et al. (1997), where an accelerated integration was applied to achieve equilibrium in the deep ocean.

\section{b. Effects of the mixed layer process (EXPs A1, B1, and $C 1$ )}

In this section we compare the effects of the mixed layer process based on the results from OGCMs with constant vertical eddy diffusivity and viscosity (EXP A1), with the Pacanowski and Philander (PP) scheme (EXP B1), and with the new OMLM described in section 2 (EXP C1).

Figures 7 and 8 show the global distributions of SST anomalies from the observed distribution for the cases of the annual mean, January, and July from EXPs B1 and C1. They clearly show, together with Fig. 3, that the seasonal variation of SST anomaly is significantly affected by the vertical mixing process. The most remarkable improvement due to including the new OMLM is the disappearance of the strong seasonal bias observed in EXP A1.

Although considerable improvement is obtained in EXP B1 (Fig. 7), the results from the PP scheme still show an overestimated amplitude of SST cycle. In particular, they give poor results near the ACC where the wind stress is strong (Trenberth et al. 1989), thus leading to poor performance in the SST cycle in the Southern Hemisphere. Note that the PP scheme does not account for the effects of wind stress on vertical mixing. Also, the PP scheme causes a rather large SST anomaly in the eastern Pacific where SST is known to be affected by the seasonally varying wind stress (Chen et al. 1994).

On the other hand, it is observed that inclusion of the new OMLM increases slightly the SST anomaly in regions where the simulated circulation deviates from the real circulation, such as the regions of the western boundary current separation. With the inclusion of OMLM the values of $K_{M}$ and $K_{H}$ vary in space and time, and therefore the inaccurate prediction of the ocean circulation may exacerbate the situation.

In order to represent the performance of different vertical mixing schemes in the OGCM more quantitatively we obtained both seasonal variations of the mean SST (Fig. 9) and the rms SST anomaly (Fig. 10) for both 
(a) January

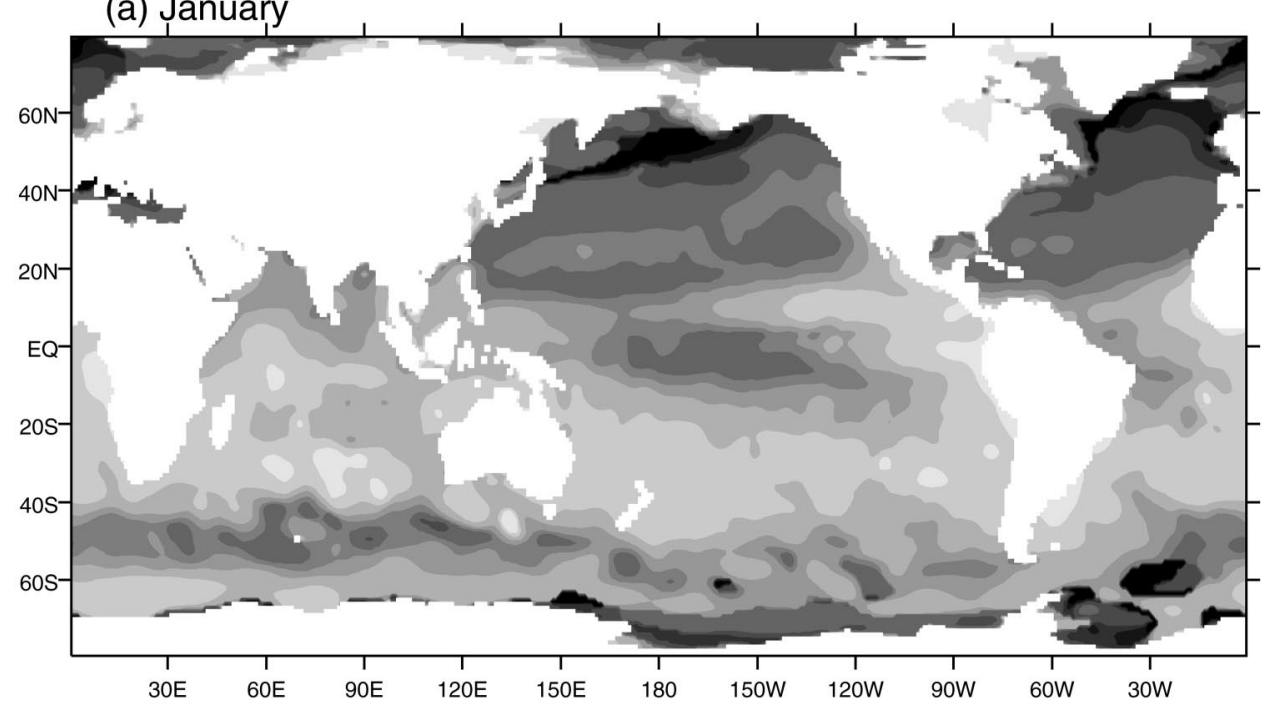

(b) July

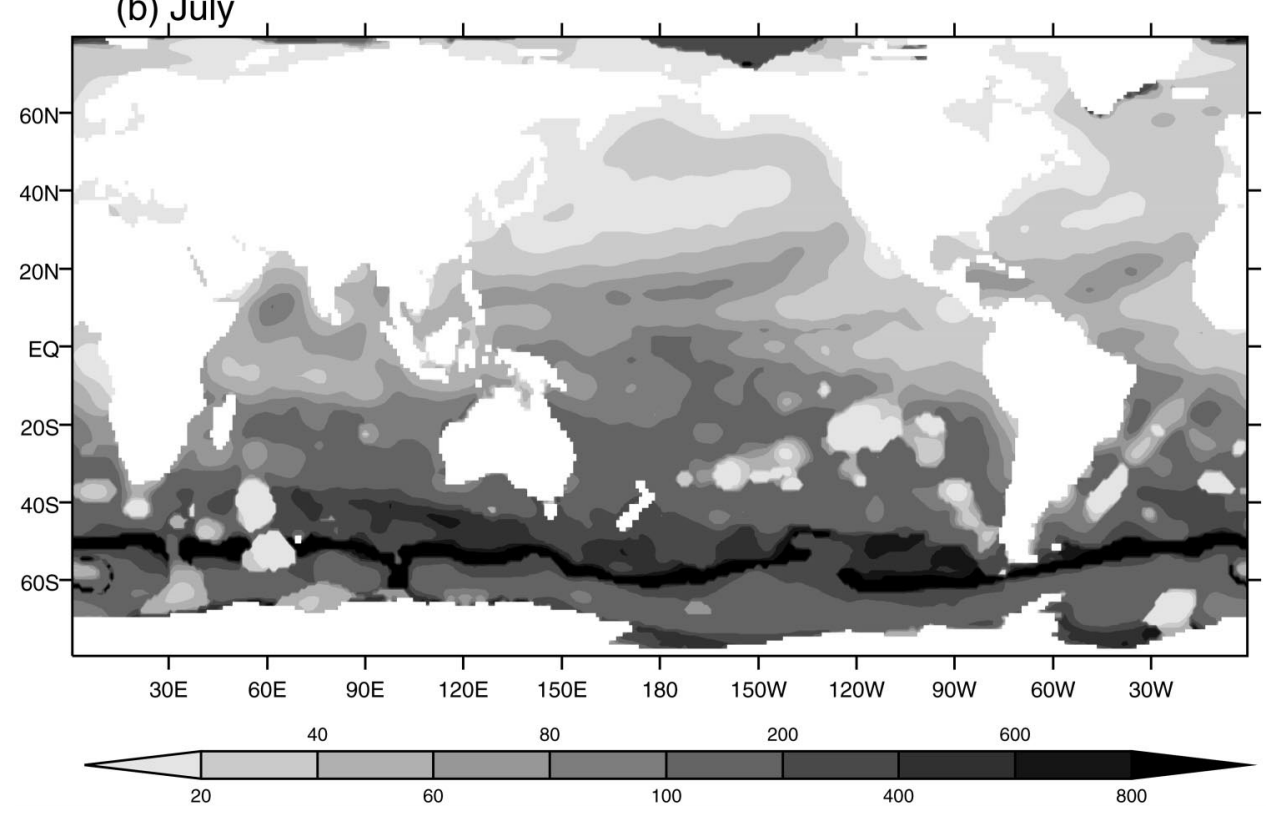

FIG. 13. Distributions of the MLD (m) (climatology). MLD is defined by the depth of the temperature difference $1{ }^{\circ} \mathrm{C}$ from SST: (a) Jan and (b) Jul.

hemispheres and the equatorial region. The rms SST anomaly may represent the actual performance in the present OGCM (Fig. 10), but these values also include the error due to the inaccurate circulation, as mentioned in the previous section. On the other hand, the general performance of vertical mixing scheme, that is, how the SST over the global ocean responds to the surface heating and cooling in the one dimensional sense, may be judged by seasonal variations of the mean SST (Fig. 9). Both Figs. 9 and 10 clearly show that the prediction of SST could be improved significantly by introducing a new OMLM in all regions.

To summarize the results shown in Fig. 9, the rms difference of the regional mean SST from the obser- vation data, which is given by $\left[\sum_{i=1}^{12}\left(\bar{T}_{i}-\bar{T}_{i}^{*}\right)^{2} / 12\right]^{1 / 2}$, where the overbar represents the regional mean and $i$ represents a month, was calculated and the results are listed in Table 1. Similarly annual mean values of the rms difference of the simulated SST from the observed data, as shown in Fig. 10, are listed in Table 2. These data again corroborate the improvement of the performance with the new OMLM. Note that the performance of the rms difference of SST is not as good as that of the mean SST, because it includes the error owing to the inaccurate circulation. Moreover, the effect of the inaccurate circulation on the SST anomaly becomes larger in the presence of the OMLM, as mentioned earlier. 
(a) January

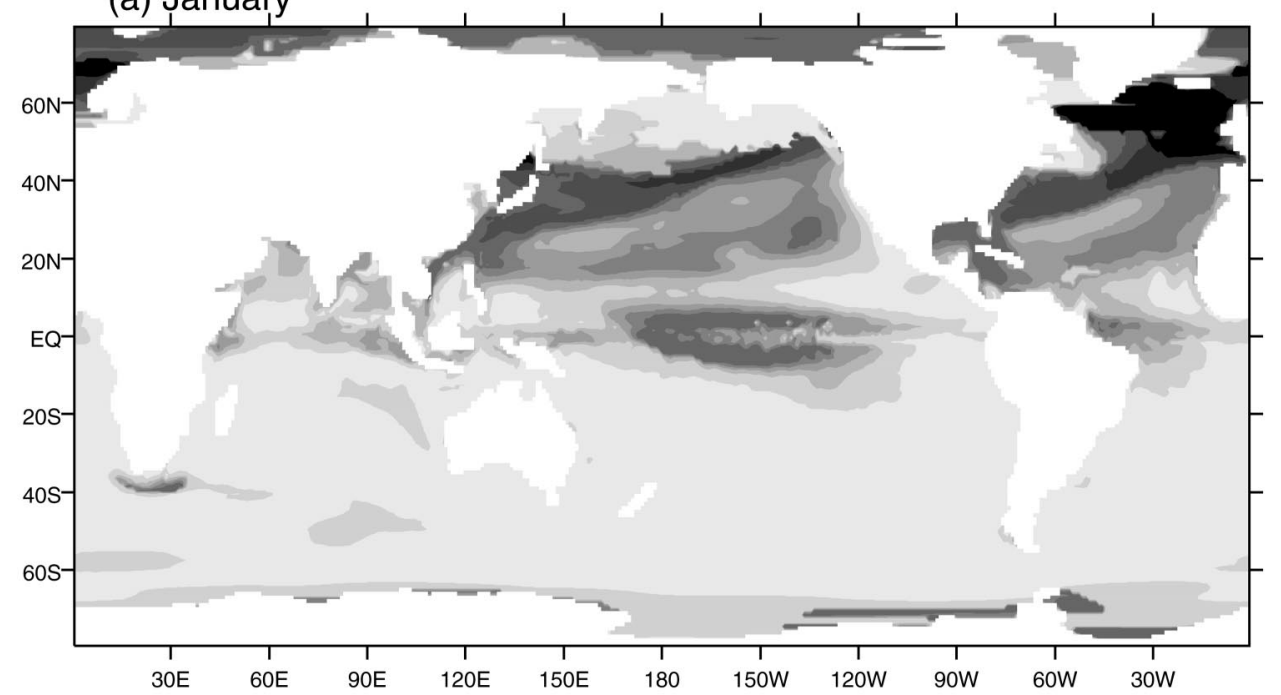

(b) July

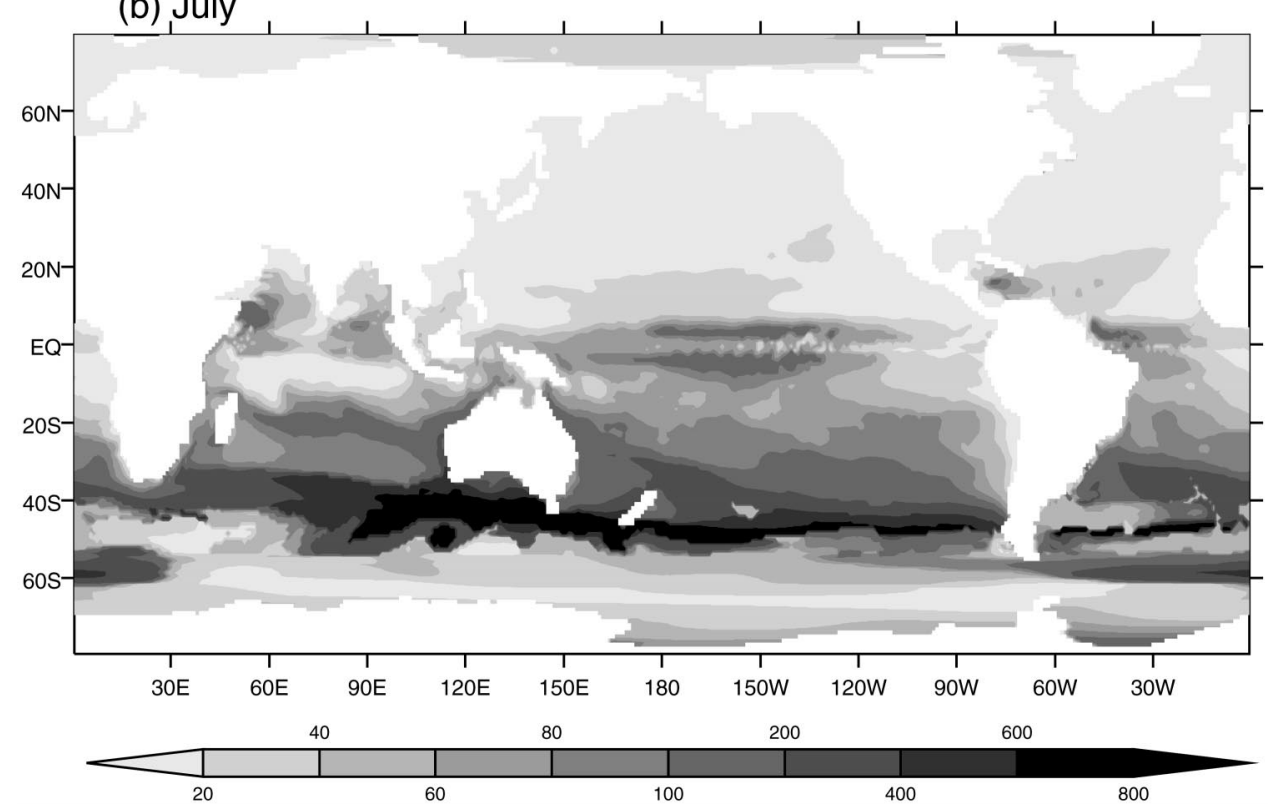

FIG. 14. As in Fig. 13 but for EXP A1.

The substantial improvement of the annual mean and seasonal cycle of SST with the new OMLM in the equatorial region is also observed in Figs. 8, 9, and 10. When an experiment was carried out with the wind stress of Hellerman and Rosenstein (1983) reduced to 0.75, as suggested by Stockdale et al. (1993) for a better prescription of the wind stress in the equatorial region, it was observed that the SST prediction in the equatorial region is improved even further (not shown).

This improvement in the equatorial region is attributed to the realization of a more realistic mixed layer in the equatorial region. The mixed layer with appropriate thickness prevents an accumulation of momentum and the consequent overestimation of the equatorial currents by distributing the momentum vertically. This helps to suppress the excessive equatorial upwelling. It can be clearly understood from the comparison of the meridional streamfunctions (Figs. 6 and 11). In the case of EXP A1 the equatorial upwelling is much stronger, and the equatorial divergence is limited to the abnormally shallow surface layer in the equatorial region. Whereas, EXP C1 shows weaker upwelling and equatorial divergence over a thickness of about $100 \mathrm{~m}$, which is comparable to the observed mixed layer depth (Halperin 1980). The reduced upwelling due to including the mixed layer process was also observed by Sterl and Kattenberg (1994). Also, it is observed that the depth to which equatorial upwelling occurs becomes shallower in EXP C1 than in EXP A1. The PP scheme shows the intermediate pattern in intensity of equatorial diver- 
(a) January

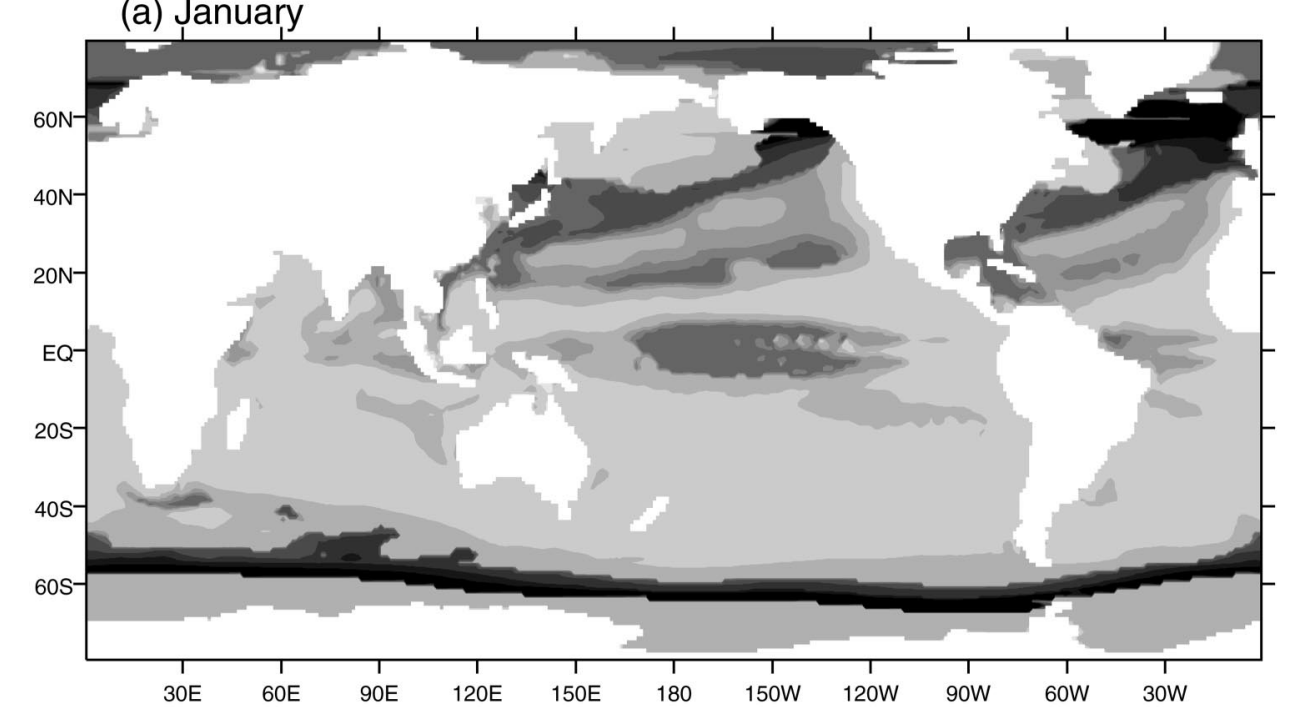

(b) July

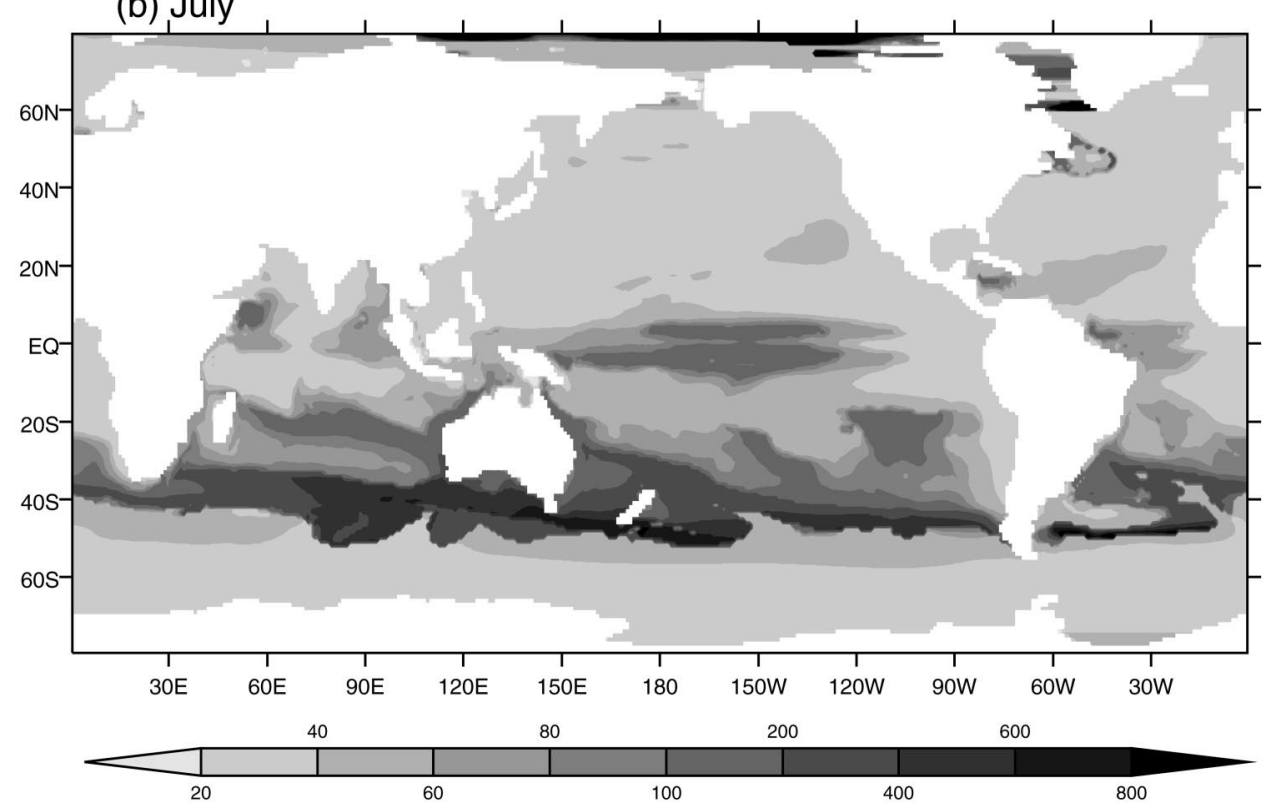

FIG. 15. As in Fig. 13 but for EXP B1.

gence, but the vertical extension of the equatorial upwelling is even smaller than in EXP C1.

To examine the effects of vertical mixing in the equatorial region in more detail, we plotted the zonal velocity distributions at about $155^{\circ} \mathrm{W}$ at the equator for three cases (Fig. 12). The observation data shows that the Equatorial Undercurrent (EUC) is generally limited between 50 and $250 \mathrm{~m}$ with maximum velocity about 90 $\mathrm{cm} \mathrm{s}^{-1}$ (Wyrtki and Kilonsky 1984). In the case of EXP A1 the EUC is vertically exaggerated and extends very close to the sea surface, which is typical in the OGCM without the mixed layer process (Semtner and Chervin 1992). On the other hand, in the case of EXP C1, the depth of the EUC is generally comparable to observations, although it tends to be slightly deeper than ob- served. Downward overextension of the EUC to a depth of about $350 \mathrm{~m}$ in both EXP A1 and EXP C1 is due to the low vertical resolution of the present model having a grid thickness of $100 \mathrm{~m}$ at that depth. The low vertical resolution may also cause the underestimation of the intensity of the EUC. The case of EXP B1 is similar to that of EXP C1, but the EUC is observed to extend downward too deep compared to the observation, suggesting improper vertical mixing below the EUC.

Annual-mean volume transport streamfunctions from both EXP B1 and EXP C1 are similar to that from EXP A1 (Fig. 1b), as expected. However, close examination of the surface velocity fields reveals that EXP A1 gives a severely overestimated equatorial current velocity of about $120 \mathrm{~cm} \mathrm{~s}^{-1}$, while EXP C1 gives a weaker velocity 
(a) January

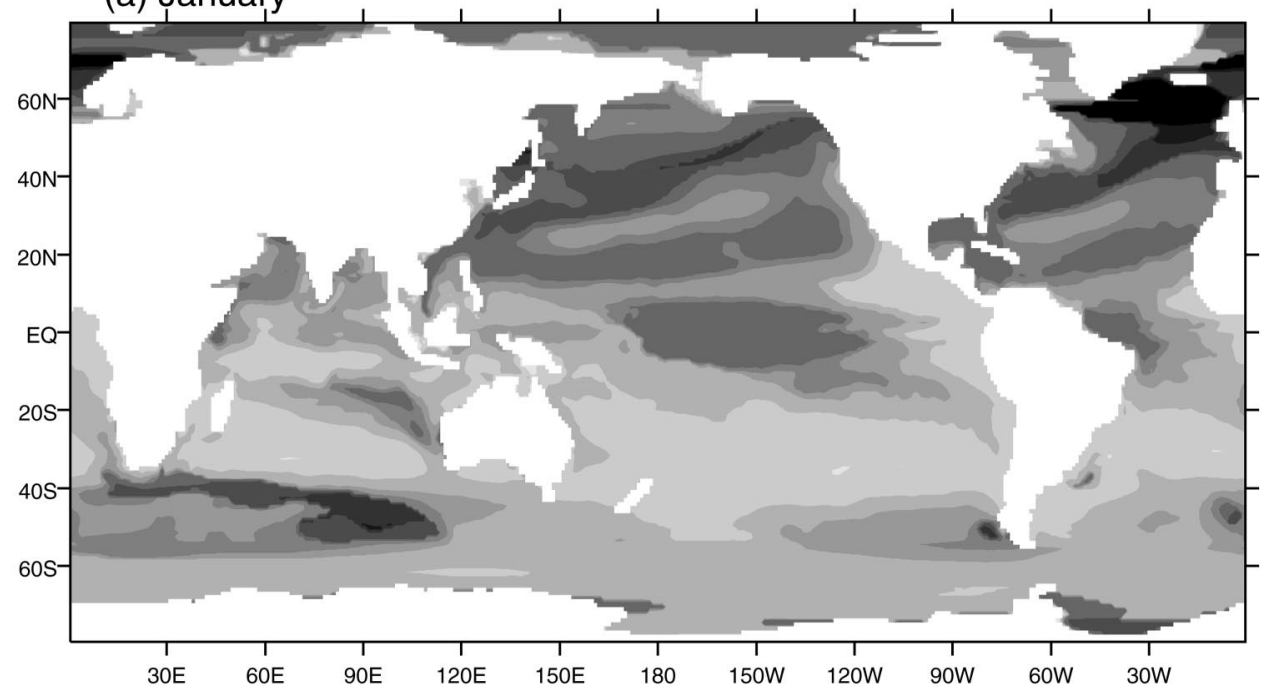

(b) July

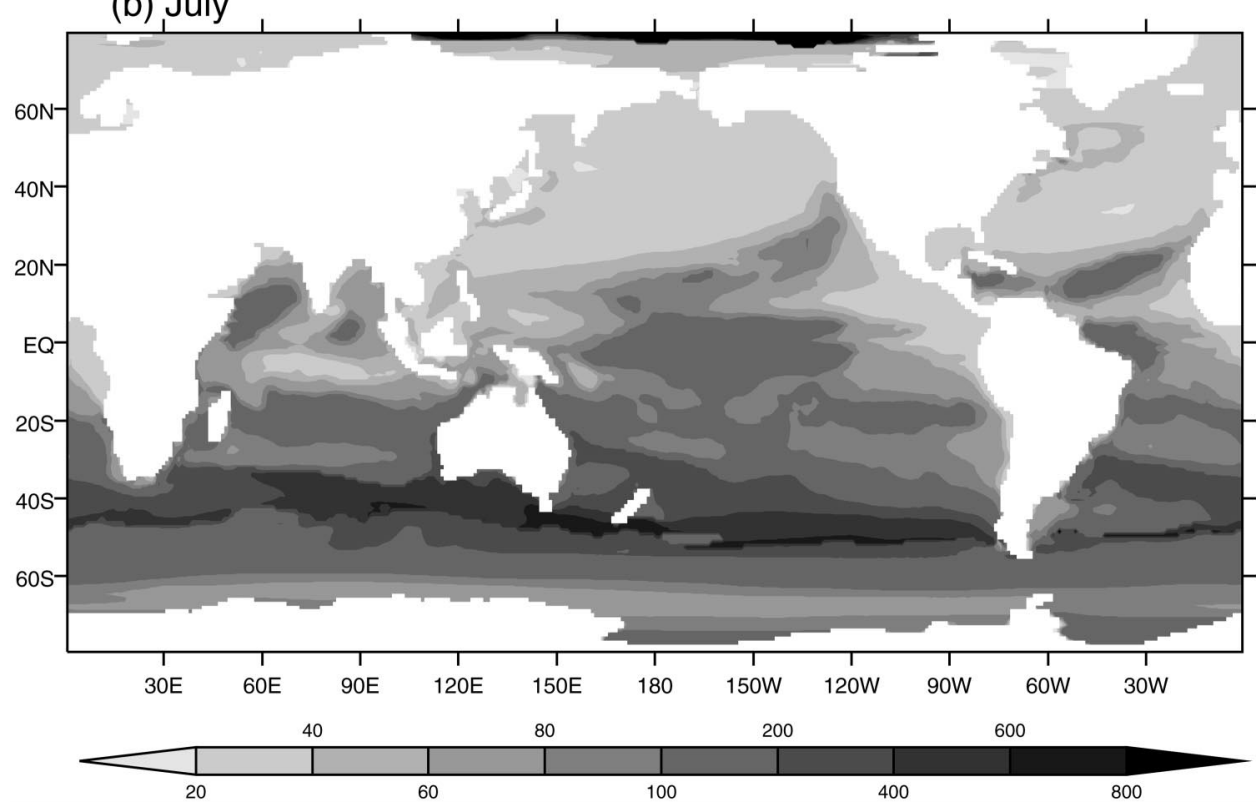

FIG. 16. As in Fig. 13 but for EXP C1. (a) Jan and (b) Jul.

of about $70 \mathrm{~cm} \mathrm{~s}^{-1}$. The observed velocity of the SEC is typically $50 \mathrm{~cm} \mathrm{~s}^{-1}$ (Reverdin et al. 1994), and it is in closer agreement with EXP C1. In addition, the equatorial currents are not zonal but show strong poleward components in EXP A1 due to the excessive upwelling. These unrealistic strong poleward components of the equatorial current also disappear in EXP C1.

An ideal OMLM should reproduce not only SST but also the internal structure of temperature below the sea surface in an OGCM. The most significant element representing this is the mixed layer depth. Figures 13-16 show the distribution of MLD both from the observation (Levitus 1982) and the simulations (EXPs A1, B1, and $\mathrm{C} 1)$. Here MLD is defined as the depth of the temperature difference of $1^{\circ} \mathrm{C}$ from SST, similarly to Rosati and Miyakoda (1988), Ezer (2000), and Sterl and Kattenberg (1994). Note that the MLD determined in this way is useful to compare subsurface temperature structures, but it can differ from a more physically relevant MLD based on the density criterion in the area where the salinity effects are important, such as in the highlatitude ocean. Note also that the definition of MLD here is different from that of $h$ in section 2 .

Neither EXP A1 nor EXP B1 could reproduce the detailed pattern of MLD originating from the surface mixing and circulation of the ocean. EXP A1 produces a too shallow mixed layer during summer owing to the absence of the well-mixed upper layer, whereas EXP $\mathrm{B} 1$ shows very poor results around the ACC, as expected from the SST anomaly (Fig. 7). 
(a)Hawaii-Tahiti Shuttle Experiment (Wyrtki and Kilonsky 1984)

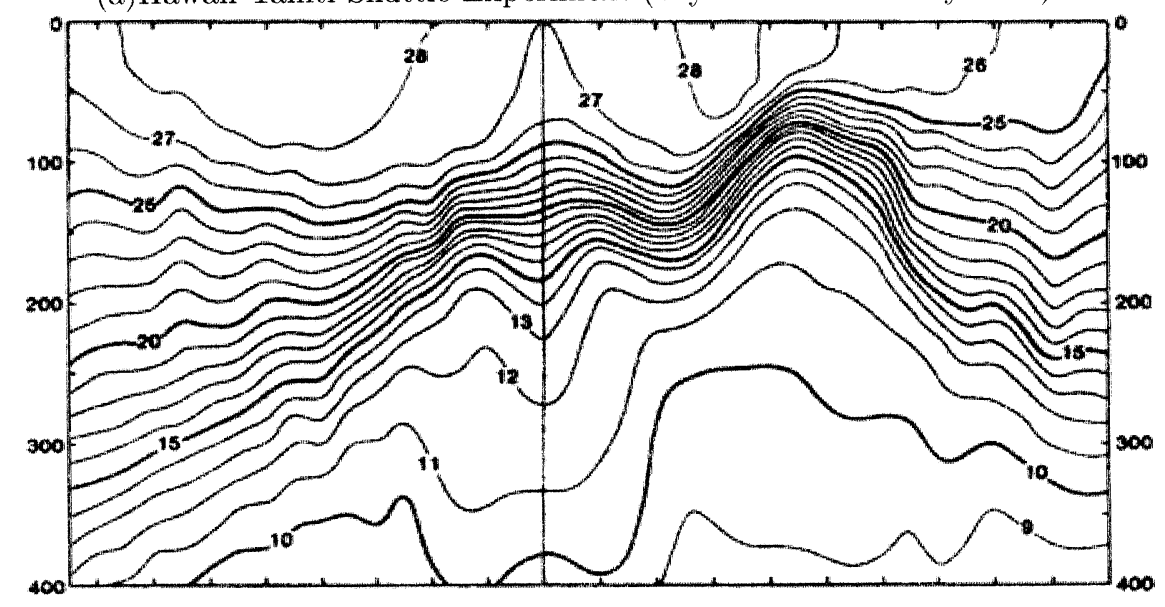

FIg. 17. Cross sections of the temperature $\left({ }^{\circ} \mathrm{C}\right)$ : (a) observation [Hawaii-Tahiti Shuttle Experiment (Wyrtki and Kilonsky 1984)], (b) EXP A1, (c) EXP B1, and (d) EXP C1.

Meanwhile, EXP C1 shows close correlation with observed data in the distribution of MLD. It is observed, however, that the simulated MLD tends to be slightly deeper in general. On the other hand, the simulated MLD in EXP C1 is not sufficiently deep in the northern Pacific, which may be related to employment of the restoring boundary condition for salinity. Since freshwater flux plays an important role in the North Pacific, the restoring boundary condition for salinity may suppress convective motion, similarly to the case for temperature. A noticeable discrepancy is also observed near the ACC because of the very weak stratification and inaccurate representation of the ACC in this region. In particular, an insufficient MLD during winter in this region might be caused by excessive diapycnal mixing due to nonisopycnal mixing and the lack of ice dynamics in the present simulation.

Cross sections of temperature also illustrate the internal structure of temperature below the sea surface (Fig. 17). Here the vertical section is confined to the upper $400 \mathrm{~m}$ of the equatorial region where the influence of vertical mixing is significant. The result from EXP $\mathrm{C} 1$ shows a more realistic temperature profile that reproduces a distinctive thermocline and more uniform mixed layer, in agreement with observation data (Wyrtki and Kilonsky 1984). The results from EXP A1 do not have a well-mixed upper layer and show a too diffused thermocline. In EXP B1 temperature decreases too rapidly below the EUC, which again indicates improper mixing below the EUC, as in Fig. 12 .

Finally, Fig. 18 represents seasonal variations of the hemispheric-mean heat flux, which is related to Fig. 9. It clearly shows that the introduction of the new OMLM reduces the contribution from the restoring term in the heat flux substantially, and is thus expected to mitigate problems caused by the restoring boundary condition.

\section{c. Effects of the restoring timescale (EXPs Cl and C2)}

We have demonstrated throughout the previous section that more realistic features of the upper ocean, such as SST, MLD, and the equatorial circulation, could be reproduced by including the new OMLM. Now we can expect that, if the OMLM really represents the vertical mixing process in the ocean correctly, it should reproduce the observed SST under a restoring timescale that is consistent with the actual feedback between the atmosphere and the ocean. That is, hopefully, we do not have to use the unrealistically small restoring timescale required to guarantee that the simulated SST does not diverse from the observed SST in the previous OGCM. So, in EXP C2 we attempted to see how the results from EXP C1 will be affected when the restoring timescale is increased to a more realistic value ( $\tau=60$ days).

Figure 19 shows the global distribution of SST anomaly from EXP C2. As expected, the simulated SST deviates further from the observed SST with weaker restoring force. However, the deviation is largely restricted to amplification of the existing anomaly of SST from EXP C1 (Fig. 8), which is caused basically by the inaccurate simulated circulation. However, the seasonal bias of the hemispheric mean SST still does not appear. This suggests that further improvement in the predictability of SST can be obtained under the present ocean mixed layer model if more accurate circulation can be reproduced. This is contrary to the case of constant vertical mixing (EXP A1), where the seasonal bias is significantly amplified with the increased restoring timescale (not shown), and thus the increased SST anomaly is expected regardless of the circulation.

Accordingly, the seasonal cycle of the hemispheric mean SST in EXP C2 (Fig. 20) does not deviate much further compared to the case of EXP C1, although the 


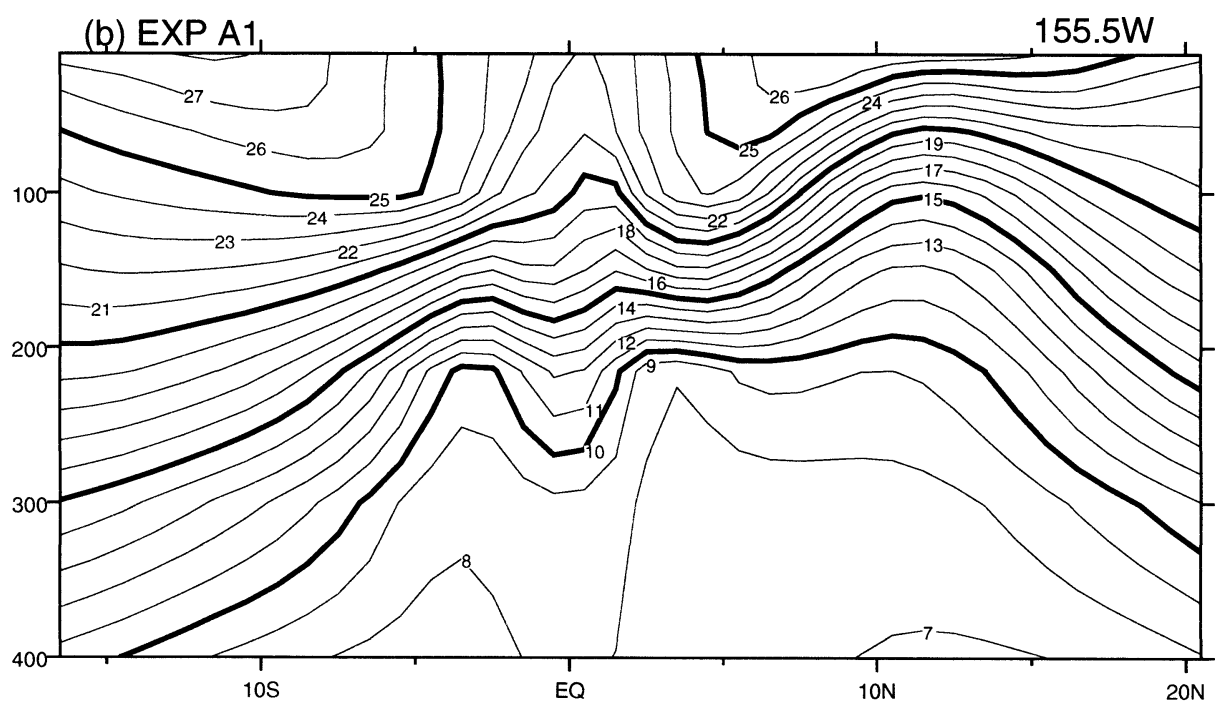

(c) EXP B1

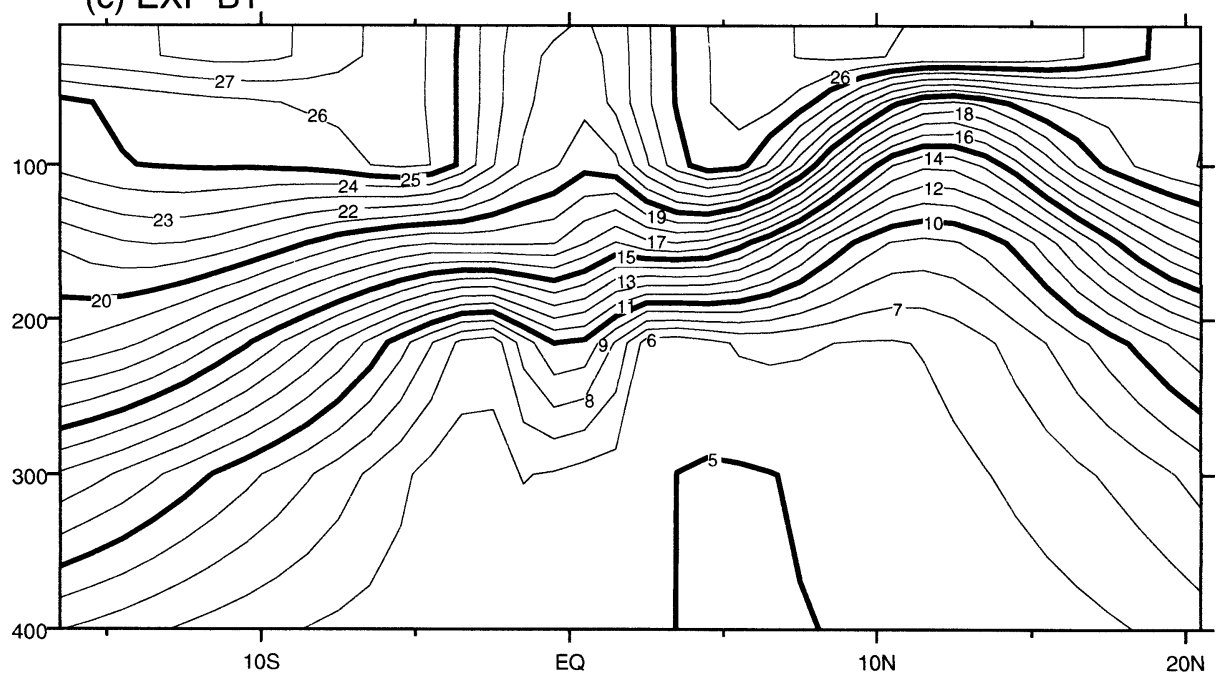

(d) EXP C1

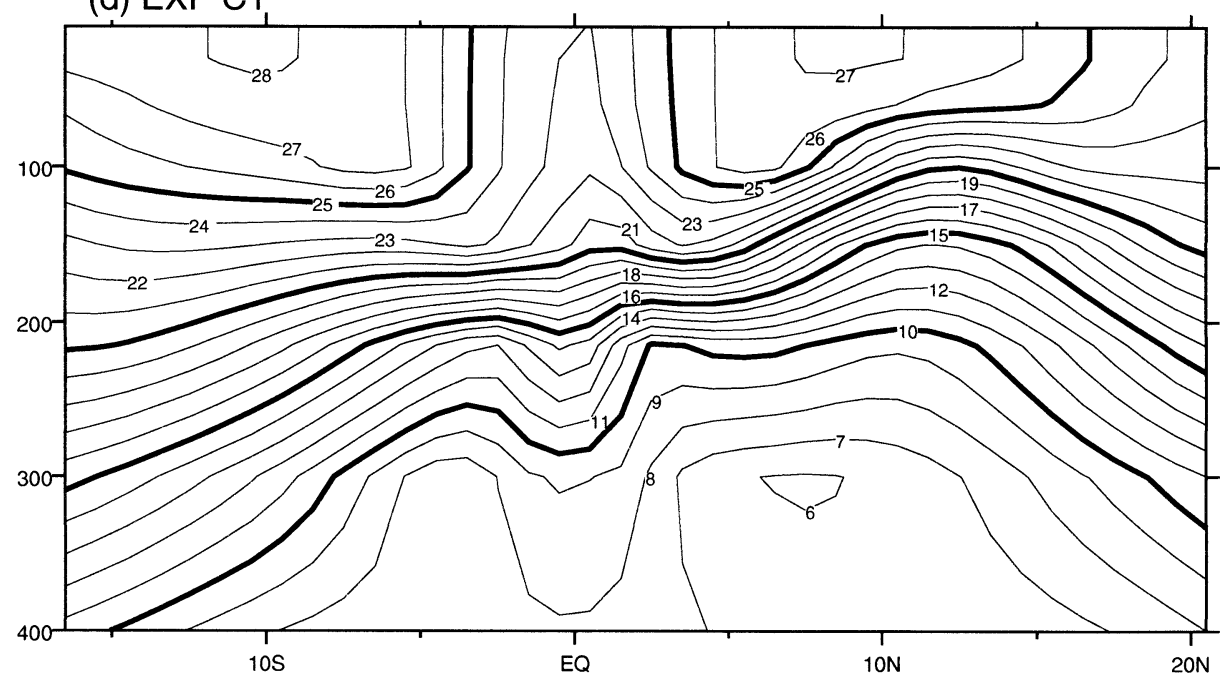

FIG. 17. (Continued) 

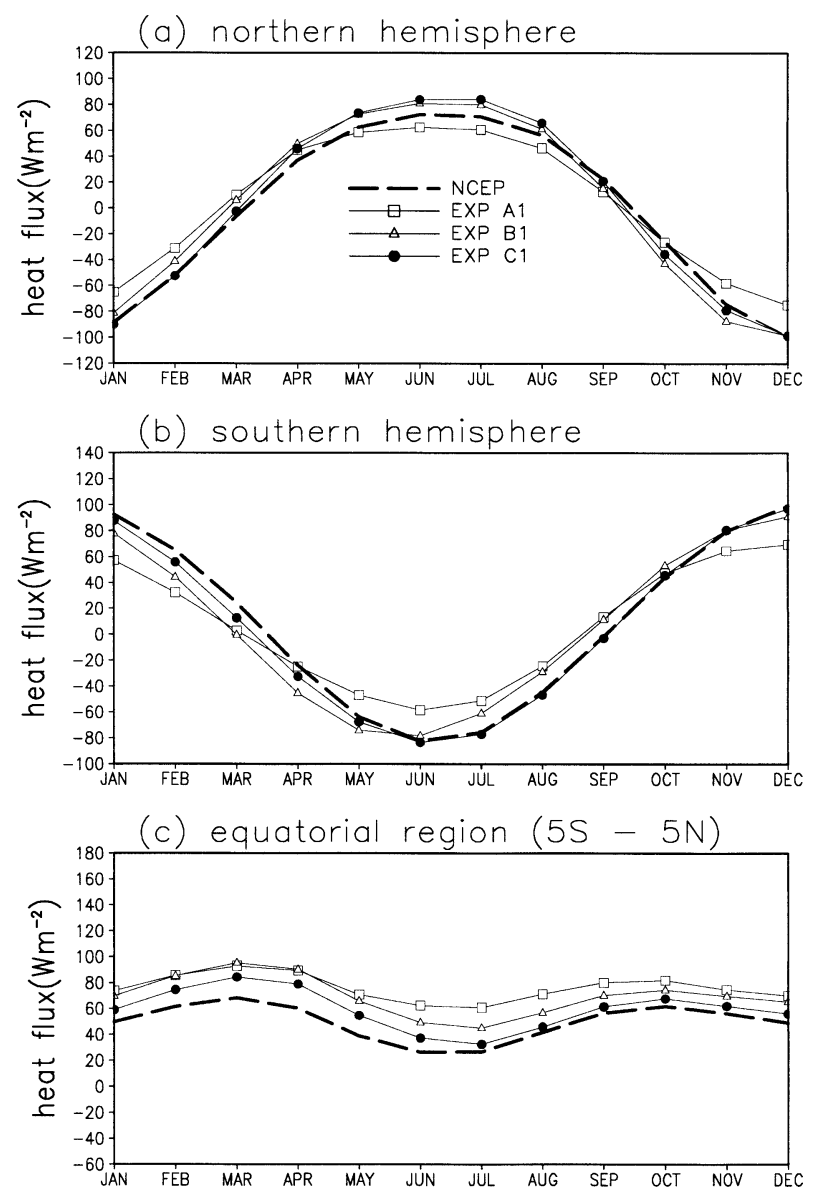

FIG. 18. Seasonal variations of the mean heat flux $\left(\mathrm{W} \mathrm{m}^{-2}\right)$ (climatology, EXP A1, EXP B1, EXP C1): (a) Northern Hemisphere, (b) Southern Hemisphere, and (c) equatorial region $\left(5^{\circ} \mathrm{S}-5^{\circ} \mathrm{N}\right)$.

rms difference of the simulated SST from the observed SST becomes much larger (not shown). Furthermore, the contribution to heat flux by the restoring term becomes even smaller than the case of EXP C1 since the restoring timescale $\tau$ in EXP C2 is twice as large as that in EXP C1 (not shown).

Meanwhile, most other aspects of the simulation such as MLD, the meridional overturing streamfunction, the surface velocity field, the volume transport streamfunction, and the cross section of zonal mean temperature remain virtually indistinguishable from those from EXP C1.

\section{Conclusions and discussion}

In this paper we have shown that prediction of the SST from an OGCM can be improved substantially by including a new OMLM. When the heat flux is given by the form of the climatological heat flux plus a restoring term toward the climatological SST, more accurate prediction of SST helps to reduce the magnitude of the restoring term, and thus relieve various problems associated with the restoring boundary condition in the
OGCM. This implies that the OGCM with a new OMLM reproduces a more natural ocean along with more realistic heat flux. In addition, the new OMLM is found to improve various other aspects of the OGCM, such as MLD and the equatorial circulation. Finally, it is shown that the new OMLM still maintains an improved level in the resultant surface heat flux and seasonal cycle of the hemispheric mean SST under a longer restoring timescale of 60 days.

Significance of the present result can be found in the fact that it may provide a more suitable OGCM for the coupling with an AGCM. We hope that accurate predictions of heat flux and SST help remove the necessity for flux correction (Meehl 1993), and the reduced artificial forcing at the sea surface will help avoid the spurious oscillating behavior when coupled with the AGCM (Cai and Chu 1996). Moreover, it is possible that the present OGCM may help resolve the problem of suppressed eddy kinetic energy in high-resolution models (Stammer et al. 1996) since the artificial restoring toward the low-resolution climatological SST is relaxed. We hope that further investigations using a high-resolution OGCM or coupled climate model can examine whether the expected improvement can be obtained in the near future.

Present research focuses on improvement of the OGCM only by improving the vertical mixing process. Nonetheless, there are many other parameterizations in the OGCM that are important for more realistic simulation of the ocean (see, e.g., Chassignet and Verron 1998). Certainly more elaborate lateral mixing can improve the simulation results further, especially in the deep convective region and the western boundary current region. On the other hand, the present research concerns mainly the simulation of the upper ocean based on the results from a relatively short period of integration (24 years). It will be interesting to investigate how the vertical mixing scheme affects the deep ocean using simulation results from a much longer period of integration.

Although prediction of SST was significantly improved by introducing the new OMLM, the simulated SST still shows a slight tendency to underestimate SST in the Northern Hemisphere and to overestimate SST in the Southern Hemisphere during summer (Fig. 9). In addition, the simulated MLD tends to be slightly deeper than observed. Further improvement may be required in both the model and the forcing data for more accurate prediction. The values of $m$ in (13) and $z_{0}$ in (14), which determine the magnitude of eddy diffusivity at the sea surface, may need elaboration, utilizing new information from the work on wave breaking and Langmuir circulation. One also needs to parameterize the effects of high frequency variability of the wind stress to evaluate $m$ and $z_{0}$ if monthly mean wind stresses are used. More realistic surface boundary conditions for both temperature and salinity are also required for further improvement. For example, improvement of the restoring 
(a) annual simulation - observation

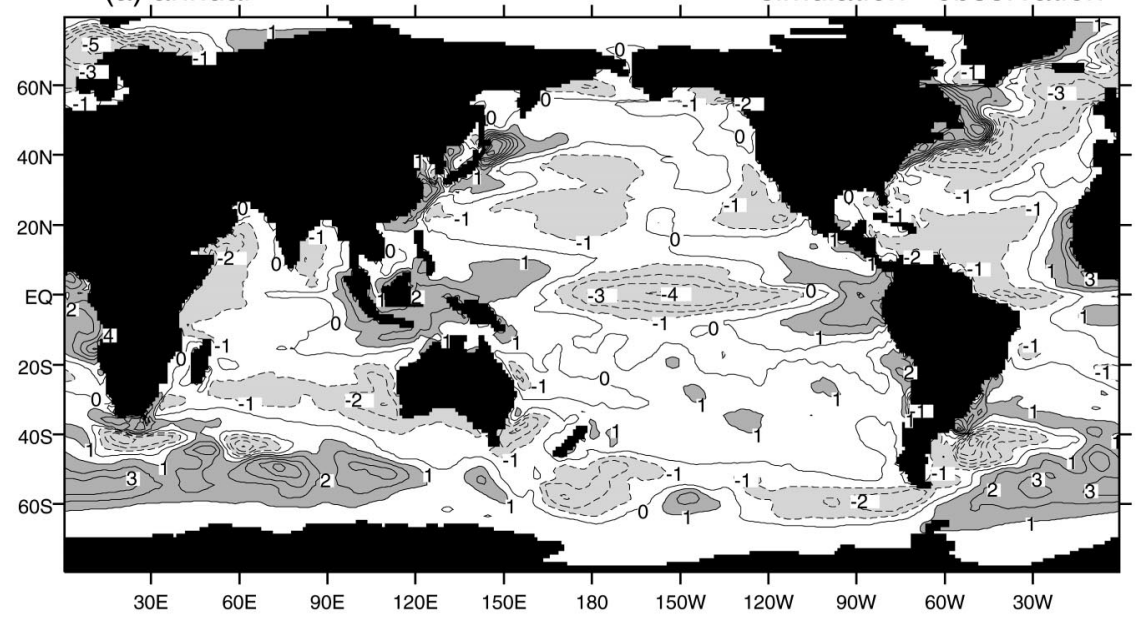

(b) January

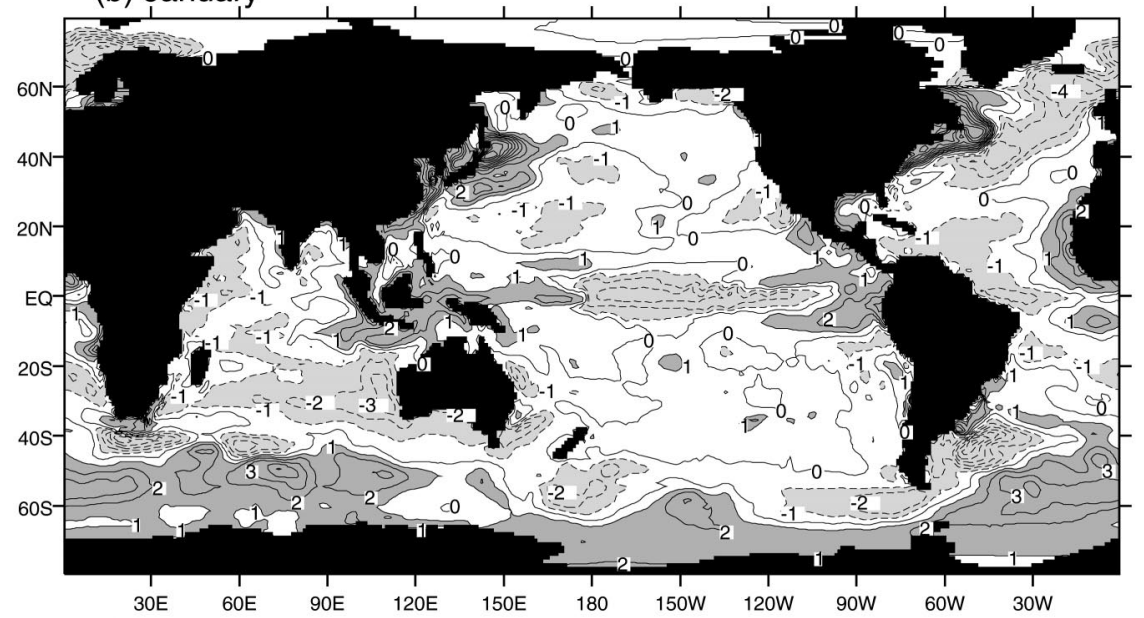

(c) July

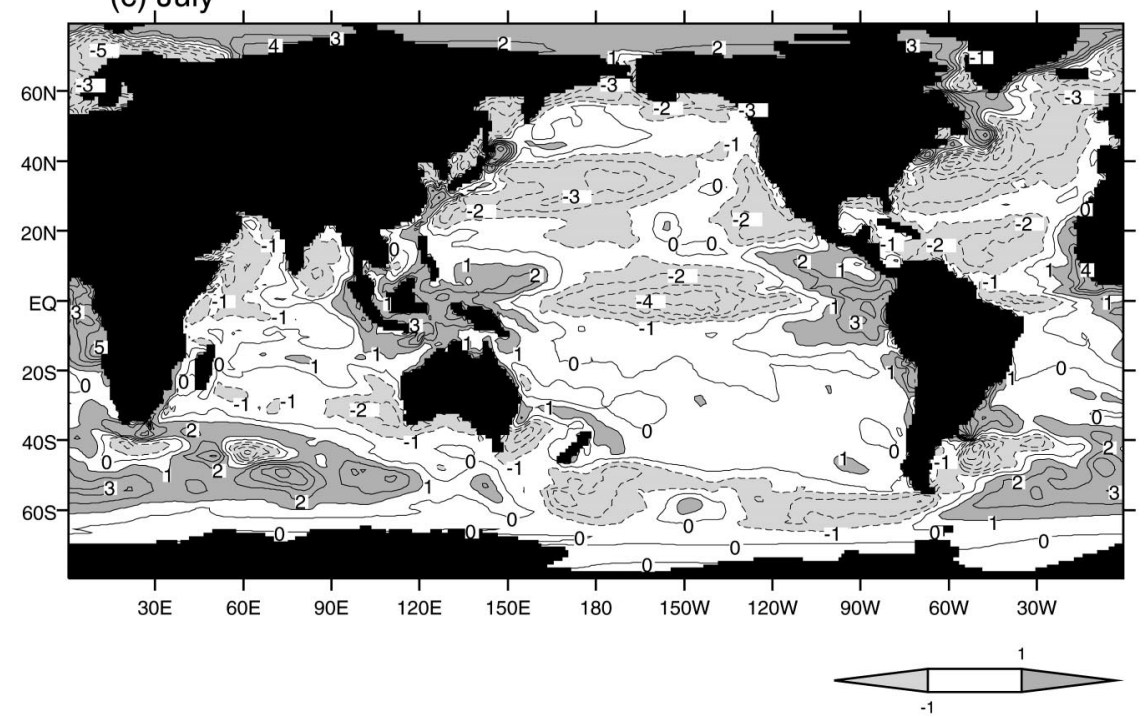

FIG. 19. Distributions of the SST anomaly (EXP C2) $\left({ }^{\circ} \mathrm{C}\right)$ : (a) annual mean, (b) Jan, and (c) Jul. 

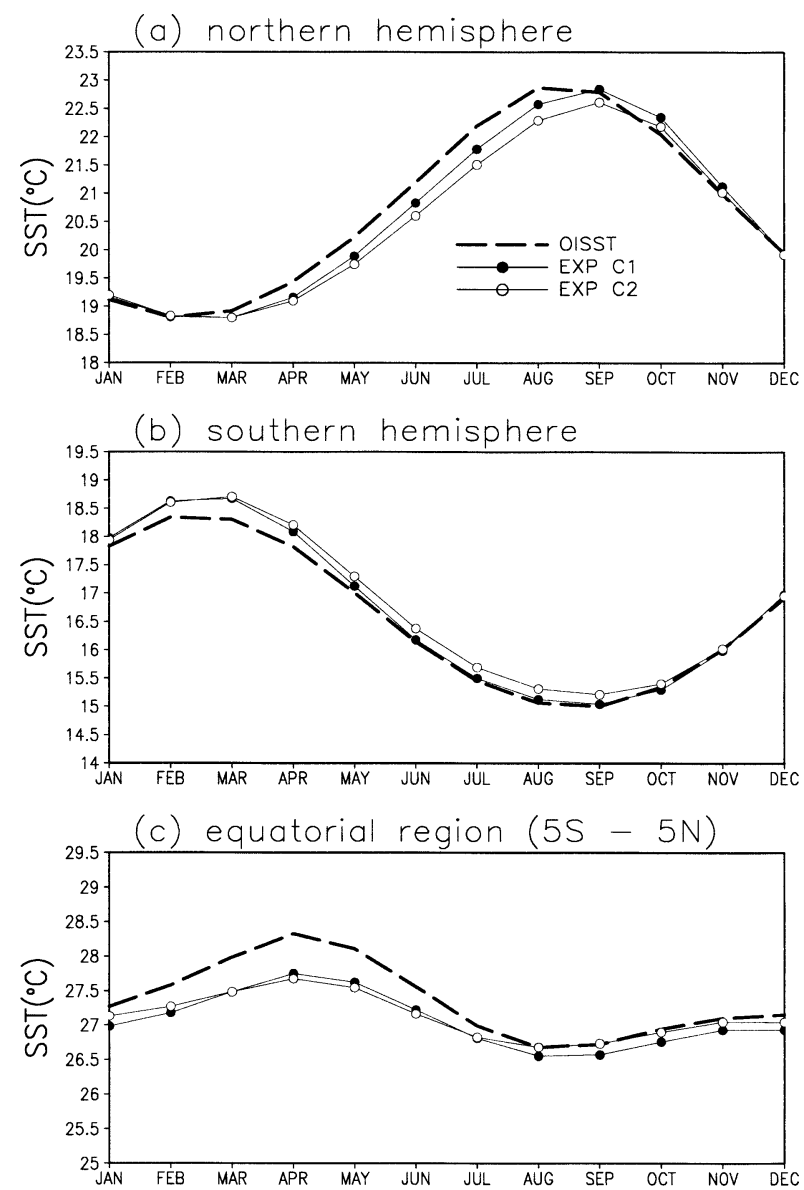

FIG. 20. As in Fig. 18 but for the mean SST $\left({ }^{\circ} \mathrm{C}\right.$ ) (climatology, EXP C1, EXP C2).

timescale can be obtained from the bulk formula for heat flux as given by (4). Finally, it is important to notice that the value of $\alpha$ in (16) and (17), representing the effects of stratification, may depend on the grid configuration of the model, as mentioned in section $2 b$.

Acknowledgments. First, we express our gratitude to Prof. J. W. Kim of Yonsei University, who inspired and supported us in the development of our OGCM with strong conviction. We are also grateful to Prof. Awaji of Kyoto University, Dr. Matsuura of NIED, and Prof. I. S. Kang of Seoul National University for their interest and critical comments. Finally, we appreciate the devoted assistance of Mr. S. T. Kim of Yonsei University during the preparation of the manuscript. This work was supported by the Korea/Japan Joint Research Project of KOSEF, the Climate Environment System Research Center sponsored by the SRC program of KOSEF and the BK21 Project (the Ministry of Education).

\section{REFERENCES}

Barnier, B., 1998: Forcing the ocean. Ocean Modeling and Parameterization, E. P. Chassignet and J. Verron, Eds., Kluwer Academic, 45-80.
— L. Liefridt, and P. Marchesiello, 1995: Thermal forcing for a global ocean circulation model using a three-year climatology of ECMWF analysis. J. Mar. Syst., 6, 36-380.

Blanke, B., and P. Delecluse, 1993: Variability of the tropical Atlantic Ocean simulated by a general circulation model with two different mixed-layer physics. J. Phys. Oceanogr., 23, 1365-1388.

Bleck, R., H. P. Hanson, D. Hu, and E. B. Kraus, 1989: Mixed layerthermocline interaction in a three-dimensional isopycnic coordinate model. J. Phys. Oceanogr., 19, 1417-1439.

Cai, W., and S. J. Godfrey, 1995: Surface heat flux parameterizations and the variability of thermohaline circulation. J. Geophys. Res. 100, 10 679-10 692

- and P. C. Chu, 1996: Ocean climate drift and interdecadal oscillation due to a change in thermal damping. J. Climate, 9, 2821-2833.

Cane, M. A., 1994: Near-surface forcing and climate. Large Eddy Simulation of Complex Engineering and Geophysical Flows, B. Galperin and S. A. Orszag, Eds., Cambridge University Press, 489-509.

Chassignet, E. P., and J. Verron, Eds., 1998: Ocean Modeling and Parameterization. Kluwer Academic, $451 \mathrm{pp}$.

Chen, D., L. M. Rothstein, and A. J. Busalacchi, 1994: A hybrid vertical mixing scheme and its application to tropical ocean models. J. Phys. Oceanogr., 24, 2156-2179.

Chu, P. C., Y. Chen, and S. Lu, 1998: On Haney-type surface thermal boundary conditions for ocean circulation models. J. Phys. Oceangr., 28, 890-901.

Craig, P. D., and M. L. Banner, 1994: Modeling wave-enhanced turbulence in the ocean surface layer. J. Phys. Oceanogr., 24, 25462559.

Drennan, W. M., M. A. Donelan, E. A. Terray, and K. B. Katsaros, 1996: Oceanic turbulence dissipation measurements in SWADE. J. Phys. Oceanogr., 26, 808-815.

Ezer, T., 2000: On the seasonal mixed layer simulated by a basinscale ocean model and the Mellor-Yamada turbulence scheme. J. Geophys. Res., 105, 16 843-16 855.

— and the separation of the Gulf Stream, induced by surface atmospheric forcing and lateral boundary flows. J. Phys. Oceanogr., 22, 660-682.

Fieux, M., C. Andrié, P. Delecluse, A. G. Ilahude, A. Kartavtseff, F Mantisi, R. Molcard, and J. Swallow, 1994: Measurements within the Pacific-Indian Oceans throughflow region. Deep-Sea Res., 41, 1091-1130.

Frankigonoul, C., A. Czaja, and B. L'Heveder, 1998: Air-sea feedback in the North Atlantic and surface boundary conditions for ocean models. J. Climate, 11, 2310-2324.

Garrett, C., and W. H. Munk, 1975: Space-time scales of internal waves: A progress report. J. Geophys. Res., 80, 291-297.

Gaspar, P., Y. Gregoris, and J. M. Lefevre, 1990: A simple eddykinetic-energy model for simulations of the ocean vertical mixing: Tests at station Papa and Long-Term Upper Ocean Study Site. J. Geophys. Res., 95, 16 179-16 193.

Godfrey, J. S., A. C. Hirst, and J. Wilkin, 1993: Why does the Indonesian Throughflow appear to originate from the North $\mathrm{Pa}$ cific? J. Phys. Oceanogr., 23, 1087-1098.

Gregg, M. C., 1989: Scaling turbulent dissipation in the thermocline. J. Geophys. Res., 94, 9686-9698.

Haidvogel, D. B., and F. O. Bryan, 1992: Ocean general circulation modeling. Climate System Modeling, K. E. Trenberth, Ed., Cambridge University Press, 371-412.

Halperin, D. A., 1980: A Pacific equatorial temperature section from $172 \mathrm{E}$ to $110 \mathrm{~W}$ during winter and spring 1979. Deep-Sea Res. 27, 931-940.

Hellerman, S., and M. Rosenstein, 1983: Normal monthly wind stress over the world ocean model. J. Phys. Oceanogr., 13, 1093-1104.

Hirst, A. C., and W. Cai, 1994: Sensitivity of a World Ocean GCM to changes in subsurface mixing parameterization. J. Phys. Oceanogr., 24, 1256-1279.

Ishikawa, Y., T. Awaji, and A. Akitomo, 1997: Global surface cir- 
culation and its kinetic energy distribution derived from drifting buoys. J. Oceanogr., 53, 489-516.

Jiang, S., P. H. Stone, and P. Malanotte-Rizzoli, 1999: An assessment of the Geophysical Fluid Dynamics Laboratory ocean model with coarse resolution: Annual mean climatology. J. Geophys. Res., 104, 25 623-25 645.

Killworth, P. D., 1989: On the parameterization of deep convection in ocean models. Parameterizations of Small-Scale Process: Proc. 'Aha Huliko'a Hawaiian Winter Workshop, Manoa, HI, University of Hawaii at Manoa, 59-74.

Klinger, B. A., J. Marshall, and U. Send, 1996: Representation of convective plumes by vertical adjustment. J. Geophys. Res., 101, $18 \quad 175-18182$.

Kraus, E. B., and J. S. Turner, 1967: A one-dimensional model of the seasonal thermocline; II. The general theory and its consequences. Tellus, 19, 98-105.

Large, W. G., and P. R. Gent, 1999: Validation of vertical mixing in an equatorial ocean model using large eddy simulation and observations. J. Phys. Oceanogr., 29, 449-464.

_, J. C. McWilliams, and S. C. Doney, 1994: Oceanic vertical mixing: A review and a model with a nonlocal boundary layer parameterization. Rev. Geophys., 32, 363-403.

_, G. Danabasoglu, S. Doney, and J. C. McWilliams, 1997: Sensitivity to surface forcing and boundary layer mixing in a global ocean model: Annual-mean climatology. J. Phys. Oceanogr., 27, $2418-2447$.

Ledwell, J. R., A. J. Watson, and C. B. Law, 1993: Evidence for slow mixing across the pycnocline from an open-ocean tracer-release experiment. Nature, 364, 701-703.

Levitus, S., 1982: Climatological Atlas of the World Ocean. NOAA Prof. Paper 13, $173 \mathrm{pp}$. and 17 microfiche.

Maltrud, M. E., R. D. Smith, A. J. Semtner, and R. C. Malone, 1998: Global eddy-resolving ocean simulations driven by 1982-1995 atmospheric winds. J. Geophys. Res., 103, 30 825-30 853.

Marotzke, J., and J. Willebrand, 1991: Multiple equilibra of the global thermohaline circulation. J. Phys. Oceanogr., 21, 1372-1385.

Masumoto, Y., and T. Yamagata, 1996: Seasonal variations of the Indonesian throughflow in a general ocean circulation model. $J$. Geophys. Res., 101, 12 287-12 293.

McWilliams, J. C., 1996: Modeling the ocean general circulation. Annu. Rev. Fluid Mech., 28, 215-248.

Meehl, G. A., 1993: Global coupled models: Atmosphere, ocean, sea ice. Climate System Modeling, K. E. Trenberth, Eds., Cambridge University Press, 555-581.

Mellor, G. L., and T. Yamada, 1982: Development of a turbulent closure model for geophysical fluid problems. Rev. Geophys., 20, 851-875.

Mikolajewicz, U., and E. Maier-Reimer, 1994: Mixed boundary conditions in the ocean general circulation models and their influence on the stability of the model's conveyor belt. J. Geophys. Res., 99, 22 633-22 644.

Noh, Y., 1996: Dynamics of diurnal thermocline formation in the oceanic mixed layer. J. Phys. Oceanogr., 26, 2183-2195.

- and H. J. Kim, 1999: Simulations of temperature and turbulence structure of the oceanic boundary layer with the improved nearsurface process. J. Geophys. Res., 104, 15 621-15 634.

Nowlin, W. D., Jr., and J. M. Klinck, 1986: The physics of the Antarctic Circumpolar Current. Rev. Geophys., 24, 469-491.

Oberhuber, J. M., 1993: Simulation of the Atlantic circulation with a coupled sea ice-mixed layer-isopycnal general circulation model. Part I: Model description. J. Phys. Oceanogr., 23, 808829.

Pacanowski, R. C., and S. G. H. Philander, 1981: Parameterization of vertical mixing in numerical models of the tropical oceans. J. Phys. Oceanogr., 11, 1443-1451.

_ K. W. Dixon, and A. Rosati, 1991: GFDL Modular Ocean Model, Users Guide Version 1.0. GFDL Tech. Rep. 2, Geophysical Fluid Dynamics Laboratory, Princeton, NJ, 46 pp.

Peters, H., M. C. Gregg, and J. M. Toole, 1988: On the parameterization of equatorial turbulence. J. Geophys. Res., 93, 11991218.

Price, J. F., R. A. Weller, and R. Pinkel, 1986: Diurnal cycling: Observations and models of the upper ocean response to diurnal heating, cooling, and wind mixing. J. Geophys. Res., 91, 84118427.

Rahmstorf, S., and J. Willebrand, 1995: The role of temperature feedback in stabilizing the thermohaline circulation. J. Phys. Oceanogr., 25, 787-805.

Reverdin, G., C. Frankignoul, E. Kestenare, and M. J. McPhaden, 1994: Seasonal variability in the surface currents of the equatorial Pacific. J. Geophys. Res., 99, 20 323-20 343.

Reynolds, R. W., and T. M. Smith, 1994: Improved global sea surface temperature analyses using optimum interpolation. J. Climate, 7, 929-948.

Rosati, A., and K. Miyakoda, 1988: A general circulation model for upper ocean simulation. J. Phys. Oceanogr., 18, 1601-1626.

Seager, R., Y. Kushnir, and M. A. Cane, 1995: On heat flux boundary conditions for ocean models. J. Phys. Oceanogr., 25, 3219-3230

Semtner, A. J., and R. M. Chervin, 1992: Ocean general circulation from an eddy-resolving model. J. Geophys. Res., 97, 5493-5550.

Stammer, D., R. Tokmakian, A. Semtner, and C. Wunsch, 1996: How well does a $1 / 4^{\circ}$ global circulation model simulate large-scale oceanic observation? J. Geophys. Res. 101, 25 779-25 811.

Sterl, A., and A. Kattenberg, 1994: Embedding a mixed layer model into an ocean general circulation model of the Atlantic: The importance of surface mixing for heat flux and temperature. $J$. Geophys. Res., 99, 14 139-14 157.

Stockdale, T., D. Anderson, M. Davery, P. Deleculuse, A. Kattenberg, Y. Kitamura, M. Latif, and T. Yamagata, 1993: Intercomparison of tropical ocean GCMs. WMO Tech. Doc. WMO/TD 545, WCRP-79, 53 pp.

Terray, E. A., M. A. Donelan, Y. C. Agrawal, W. M. Drennan, K. K. Kahma, A. J. Williams III, P. A. Hwang, and S. A. Kitaigorodskii, 1996: Estimates of kinetic energy dissipation under breaking waves. J. Phys. Oceanogr., 26, 792-807.

Toggweiler, J. R., K. Dixon, and K. Bryan, 1989: Simulations of radiocarbon in a coarse resolution world ocean model. I. Steady state prebomb distribution. J. Geophys. Res., 94, 8217-8242.

Tomczak, M., and J. S. Godfrey, 1994: Regional Oceanography: An Introduction. Pergamon.

Toole, M. O., 1998: Turbulent mixing in the ocean. Ocean Modeling and Parameterization, E. P. Chasignet and J. Vernon, Eds., Kluwer Academic, 171-190.

Trenberth, K. E., J. G. Olson, and W. G. Large, 1989: A global ocean wind stress climatology based on ECMWF analyses. NCAR Tech. Note NCAR/TN-338+ STR, 93 pp.

Wyngaard, J. C., 1985: Structure of the planetary boundary layer and implications for its modeling. J. Climate Appl. Meteor., 24, $1131-1142$

Wyrtki, K., and B. Kilonsky, 1984: Mean water and current structure during the Hawaii-Tahiti Shuttle Experiment. J. Phys. Ocean$o g r ., 14,242-254$. 